\title{
TODO LO QUE USTED QUERÍA SABER SOBRE LA COHERENCIA Y NO SE ATREVIÓ A PREgUNTARLE A AMAlia AMAYA
}

Guillermo Lariguet ${ }^{1}$

1 Conicet, CIFFYH, Universidad Nacional de Córdoba, Argentina. glariguet@yahoo.com
"Inmediatamente, comprendió la diversidad de las cosas de este mundo, y la inutilidad de esforzarse hacia las ideas. El universo le pareció semejante a aquellos copos de lana que los dedos buidos de la africana hacían revolar en torno de ella...Y en todo su cuerpo sintió un pueblo invisible y discorde, ávido de disgregarse”.

Lucrecio. Poeta. Marcel Schwob. "Pocos años después, encontraron a Paolo Uccello muerto de inanición sobre su camastro. Su rostro estaba radiante de arrugas. Sus ojos, fijos en el misterio revelado. En el puño apretado con fuerza, se encontró un redondelito de pergamino cubierto de líneas entrelazadas, que iban del centro a la circunferencia, y volvían de la circunferencia al centro".

Paolo Uccello.Pintor. Marcel Schwob. 
1. Mi contacto con Amalia Amaya no es solo el "impersonal" de quien tiene la tarea de escribir un trabajo sobre su meticuloso estudio acerca de la coherencia, principalmente en el ámbito jurídico; estudio que ha sido laureado con el premio a la mejor tesis doctoral por la Academia Europea de Teoría del Derecho. Durante mi fecunda e inolvidable estancia en el Instituto de Investigaciones Filosóficas de la UNAM tuve la oportunidad de intercambiar algunos puntos de vista sobre algunas de las 10 tesis que ella presenta a modo de resumen de su tesis de mayor extensión y aliento. Escribir un libro no es poca cosa y esto es algo que se está olvidando progresivamente en la "cultura" filosófica. Cervantes cuenta de aquel loco de Sevilla que tomó un perro y poniéndole un canuto por donde era posible inflarlo como pelota para luego darle palmaditas en la panza, preguntaba a los circunstantes "¿pensarán vuesas mercedes ahora que es poco trabajo hinchar un perro? ¿Pensará vuesa merced ahora que es poco trabajo hacer un libro? (citado por Platts, 1998: 249). La pregunta de Cervantes reluce como un diamante por un dato que Bernard de Mandeville observó con implacable rigor: "Los hombres de letras que trabajan bajo el influjo de ese desasosiego experimentan síntomas completamente diferentes. Cuando envidian a una persona por sus prendas y erudición, su principal cuidado es ocultar habilidosamente esta debilidad, empezando generalmente por negar y despreciar las buenas cualidades que envidian: escudriñan con cuidado las obras de sus víctimas, encuentran defectos en los mejores pasajes, no buscan más que errores y no desean otra cosa que regalarse con una equivocación evidente..." (citado por Platts, 1998: 249). No es inusual que en la discusión -filosófica en este caso- este tipo de situaciones existan y que incluso, lamentablemente, nos hayan dominado alguna vez a título de emociones incontrolables (más adelante diré algo sobre emociones).

El lector podrá preguntarse a esta altura: ¿y todo este prólogo a qué cuento viene? Viene a cuento de un primer acto de cortesía con la obra que interpelaré; no hacerlo, sería equivalente a hacer pasar directamente a la cocina a alguien que hemos invitado a comer.

Quiero ponerme en la situación verosímil para un lector que no conoce en detalle la propuesta de Amaya y quiere ir más allá de su 
memoria de 10 tesis, de ese lector que está ávido por saber temas centrales sobre la coherencia, conectados directa o indirectamente con las mencionadas tesis, pero que necesita más respuestas de Amaya. Yo me atreveré, en nombre de ese agudo público, a realizar una serie de comentarios, y al hilo de los mismos, efectuarle preguntas a Amaya cuya respuesta me interesa conocer. Espero que los comentarios y preguntas que haré se muevan bajo el juego de un cortés intercambio mediado por el disfrute de un té ceilandés, aunque, por supuesto, a veces pueda resultar del todo imposible evitar echar mano de aguardiente (o tequila o ginebra, quizás para Amaya, y ajenjo, quizás para mí) cuando las preguntas sean más candentes. El lector sabrá si necesita algo más que aguardiente, tequila o ajenjo para pasar mis páginas.

2. Sería un razonamiento impenitente pensar, en primer término, que la "teoría de la coherencia" no haya sido original y principalmente una teoría de la "verdad" que, convengamos, tanto amantes como detractores, aceptan que es un concepto central de la filosofía (Engel, 2002:1-2) en cualquier campo que sea (teorías, significado, inferencia, etc.). Algunos filósofos hoy tienden a aligerar un compromiso tan fuerte con la verdad y a conectar la coherencia con otros sucedáneos aparentemente más distanciados de ésta y así hablan de "inteligibilidad", "objetividad", "armonía", etc. En segundo término sería algo ingenuo pensar que la teoría de la coherencia haya sido por lejos la teoría filosófica dominante. La misma surgió como alternativa a la teoría de la "correspondencia" o, como decían los filósofos medievales, de la "adecuación del intelecto a una cosa". La correspondencia se representa si digo "P es verdadero syss P". Ya casi por aquella inercia o avaricia de acariciar el mismo oro acariciado de siempre, como decía Bachelard, el ejemplo convocado para representar aquella simple fórmula acaba siendo, casi siempre, "La nieve es blanca sólo si es blanca". Muchos filósofos pensaron que representar qué es la verdad en estos términos mostraba la reverberación de la vacuidad y

${ }^{2}$ Sobre todo si se es escéptico respecto de que pueda hablarse de verdad o falsedad de "normas", admitiendo que sólo podría hacérselo de proposiciones que describan normas. Este es un tema sobre el que Amaya no se explaya en su memoria. 
todos nos quedábamos sin saber, finalmente, qué era la verdad. Posiblemente por esto, Heidegger, remontándose a fuentes griegas, quería algo más "sustantivo" para la verdad, y sostenía que la alètheia era la "develación del ser" (Engel, 2002: 4). Sin embargo, el promontorio dificultoso, saber qué es la verdad, seguía en el mismo lugar porque sólo veíamos una ingenua equivalencia en decir "que es verdad que la nieve es blanca sí y sólo sí la nieve es blanca". Esto condujo a pensar en definiciones minimalistas de la verdad que algunos creen ya encontrar en la definición clásica de verdad que brindó Aristóteles (2000) en Metafísica: "decir de algo que es, que es y que no es, que no es, eso es verdad". Este minimalismo, con todo, no calmó las obsesiones de Frege, quien declaró que la verdad era realmente un concepto primitivo y por tanto "indefinible", (Engel, 2002: 6) parecido a si yo sostuviera el truísmo de "p es verdadero =p", donde "p" sería el signo de exhaustividad de lo que es el mundo. Quine trató de esquivar la idea de indefinibilidad pero propuso lo que hoy conocemos como la teoría de la "descitación" (disquotational theory) que no es otra cosa que "descitar la sentencia que dice que $\mathrm{P}$ a partir de una sentencia que lleva en su interior a P". Esta estrategia deflacionista no era otra cosa que la presentación de un escenario que escondía tras de sí la principal lucha metafísica, a saber: acerca de hasta qué punto es plausible ser un antirrealista en materia de verdad como se descuelga aparentemente de la estrategia minimalista o descitacionista o si, en cambio, lo adecuado es mantenerse en la tradición realista fuerte, sosteniendo que la verdad presupone un ajuste de nuestros contenidos mentales (típicamente creencias) con un mundo que nos resulta independiente y soberano respecto de las operaciones a menudo distorsivas que practicamos con nuestras creencias. Parte importante del problema con la teoría de la correspondencia tenía una explicación en una cuestión epistemológica de vieja data, enraizada en el empirismo. La cuestión se basaba en la acusación de que la verdad como correspondencia presuponía, como alegaba Sellars, la instauración del dogma o "mito de lo dado" (Kalpokas, 2008: 281-302). El empirismo, al parecer, no puede dar cuenta de cómo diablos justificamos nuestros juicios mentales en la experiencia: en lo dado. La respuesta clásica era que entre nuestros juicios y el mundo había "filtros" (que recibieron nombres diversos en 
la historia de la filosofía) que nos permitían "espejar" adecuadamente el mundo en nuestros juicios. Autores a la Rorty impugnaron este mito sosteniendo que lo dado jamás puede ser juez de nuestros juicios ya que su único papel es generarnos impactos causales vía nuestras sensaciones, impresiones, etc. Pero no hay relación "lógica" entre preceptos de naturaleza diferente: los hechos por un lado y las creencias por el otro. Estas relaciones lógicas sólo pueden darse entre juicios o creencias (que comparten la misma naturaleza). Estas relaciones, a las que se les puso el mote de "lógicas", no debían ser pensadas exclusivamente como de "consistencia" sino como algo más amplio, como relaciones de "coherencia", de apoyo mutuo entre enunciados; apoyo que vamos logrando en el marco de una forma de vida o comunidad de habla en la que compartimos algunos supuestos fundamentales que hacen posible una conversación (Rorty, 1996) o un juego de dar y pedir razones ${ }^{3}$ (Brandom, 2001). El propósito de estos juegos no es tanto la "verdad", cuanto la posibilidad de lograr consensos útiles o solidarios con los próximos, con los que están dispuestos o programados a converger con nosotros o con los que aceptan internamente normas de cierto juego. Sin embargo, la teoría de la coherencia como nuevo monarca filosófico no había calmado lo que McDowell (2003) llamó nuestra "angustia filosófica", a saber: que el mundo se nos escurra entre los dedos y perdamos objetividad (McDowell, 1997: 157-1624). Si ya no es el mundo la piedra de toque de corrección de los juicios sino sólo el "soporte mutuo" que estos se brindan entre sí, ¿qué aleja confiablemente el temor de que la coherencia sea sólo una máscara que encubra la

${ }^{3}$ En este juego es crucial para Brandom que haya alguien que en la práctica de dar y pedir razones "lleve la cuenta": sea una suerte de vigilante de que el juego funcione correctamente. Aplicando la categoría brandomiana sería importante intentar reconstruir quién lleva esta cuenta en prácticas éticas, políticas y jurídicas.

${ }^{4}$ Justamente, McDowell duda que el "inferencialismo" -una de las versiones de las teorías coherentistas- garantice objetividad. Aunque Brandom es un "analítico-hegeliano", pace las críticas de Russell al hegelianismo, McDowell también tiene compromisos hegelianos, solo que no quiere perder contacto con el mundo, sin caer por ello en el mito de lo dado. El giro será, vía Sellars, recuperar un espacio de las razones o los conceptos tal como ya Kant demandaba. El tema es más complejo. Véase Redding, 2007. 
reunión de un grupo de juicios o creencias descabelladas o arbitrarias acerca no sólo de la organización de la esfera celeste sino acerca de cuestiones morales que nos importan? ¿Sería posible presentar un conjunto de normas morales o legales que defiendan el nazismo como coherentes? Este tipo de preguntas se presentan con insaciable persistencia y por esto Amaya sostendrá en su trabajo que una manera de conjurar el peligro es echando mano de la "inferencia a la mejor explicación" realizada a partir de un "requisito observacional" que resulte confiable. Lo primero que me atrevería a preguntarle a ella es si al dar este paso no ha desertado de su propuesta de una teoría de la coherencia, al comprometerse con elementos que están fuera de la red de araña que la misma configura. Justamente, Amaya señala que un problema de las teorías de la coherencia es su "aislamiento" del mundo y esto problematiza el importante tema de la "genealogía" de los enunciados que formarán la "base" del sistema que quiere re-presentarse como coherente. Nos importa, diría Amaya, el tema los "inputs" que introducimos a un sistema. Nos interesa que sean creencias confiables, estables. Ahora bien, uno podría pensar entonces que lo que Amaya dice plantea el siguiente problema. La coherencia, entre otras facetas, podría ser pensada como una metáfora de la "justificación" en el sentido rortyano de que no hay nada mejor para una creencia que otra creencia (algo así dicen los peronistas argentinos aunque no sean pragmáticamente coherentes en sus prácticas, pero este es otro rollo). Dicho de un modo técnico: una creencia se "justifica" en otra creencia. Pero esta justificación es "interna" a la red de creencias en cuestión. Pero entonces, la apelación a la cuestión de la génesis o inputs, al tema de que los contenidos de las creencias sean "confiables", introduce un "mordisco sustantivo" a la teoría de la coherencia defendida por Amaya y mis preguntas aquí son ahora estas dos: Primero, ¿no está añadiendo Amaya a su esquema coherentista de justificación propiamente interno un criterio de "validez" o "corrección" (digamos sin ambages ijustificación!) que complejiza su propuesta de un modo que ella tiene que explicarnos cuál es al final su teoría de la justificación de creencias? Segundo, cuando Amaya opera con la expresión "confiable", y aquí la seguiré literalmente, ¿en qué tipo o tipos de "confiabilidad" medita? En ciencias puramente empíricas es de suponer que esta confiabilidad 
dependería de lo que ella misma llama "requisitos de observación”. Esta es una respuesta, por otra parte, algo simple, si uno recuerda que la observación puede estar preñada de categorías conceptuales y entonces ahora queremos saber también cuán confiables son estas categorías. Pero en ética, política o derecho, ¿de qué material habrá de depender esta confiabilidad, de modo tal que no se trate de un mecanismo puramente "intuicionista"? Precisamente, ciertas respuestas incongruentes que los teóricos de la coherencia han dado a este tipo de preguntas han hecho pensar cuán cerca podrían estar las teorías de la coherencia (al menos algunas) de ciertas versiones posmodernas del estilo Rorty o, por qué no, del estilo Foucault. Si, por hipótesis, varios sistemas rivales pueden mostrarse como coherentes, y no hay manera de establecer cuál es el mejor (o el menos malo), ¿no será que, en realidad, el discursillo de la justificación es el velo de cosas más importantes de las que deberíamos ocuparnos, tales como el uso que cierta gente hace de la coherencia para legitimar su lucha por el poder? Aunque al final de mi trabajo regresaré a una parte de esta sugestión, diría por lo pronto que los critical legal schorlaships, para solo citar un caso, podrían sentirse identificados con el sentido de esta pregunta.

3. Pienso que la pregunta anterior no debe ser desdeñada. En cualquier caso, creo que tenemos que resistir (¿la fácil?) tentación de aceptar el enfoque que presupone aquella pregunta; enfoque que nos deja con un nudo poder y con afirmaciones acerca del mismo que son puramente interesadas, faltas de objetividad. La tentación debe ser resistida por lo siguiente. Este mismo enfoque subjetivista o ideologista, que pretende jaquear nuestras ideas acerca de la confiabilidad de un sistema coherente, debe presentarse en las discusiones sustantivas internas de nuestras prácticas como un enfoque también "objetivo" soriesgo de cometer una auto contradicción lógica (Nagel, 2000). Debería ser obvio: decir que todo es subjetivo tiene que ser también un juicio objetivo en competencia con los otros enfoques rivales disponibles en una práctica (la teoría de la correspondencia, la descitacionista o deflacionista, la coherentista, etc.). Pero no avancemos corriendo. He planteado que la teoría de la coherencia responde que la justificación (otros preferirán hablar de verdad a secas) de las creencias depende del 
soporte mutuo de ajuste y reajuste entre estas creencias. Se trata de un modelo donde las creencias, al morderse la cola, intentan escapar al clásico modelo fundacionista linear del conocimiento (Audi, 2003: capítulo 7; Dancy; 1985: capítulo 7; para el caso del Derecho, véase Pérez Bermejo, 2006). Ahora bien, Amaya habrá de perdonarme mi posible barbarismo si le confieso que nunca he terminado de entender bien (quizás por cierta impericia filosófica) cómo entender la idea de "soporte mutuo", soporte que explique la justificación. Como más adelante me ocuparé de esta duda con algo más de detalle, quiero insistir en la cuestión de la confianza en el contenido de las creencias de esa red de soporte mutuo. Como he sugerido, mi sospecha es que la movida de Amaya peligrosamente -para su propia coherencia- la lleva "fuera" de la red. Una respuesta, sin embargo, en la que ella podría insistir es la siguiente. Existe un test para saber si las creencias de la red son confiables. Este test consiste en atender a las observaciones que me lleven a las mejores explicaciones. ¿Pero cómo saber cuáles son estas observaciones? La respuesta tendría que ser: son aquellas que permitan inferencias a la mejor explicación. ¿Pero cómo es posible esta mejor explicación? Pues no sólo dependerá de usar cadenas inductivas -o abductivas- apropiadas sino también de partir de las mejores observaciones. Pero, ¿no seguimos extrañamente en el círculo que quiero comprender? Por lo pronto, quisiera recordar que hablar de "observación", por ejemplo en ética, expresa una manera de pensar algo ríspida: si tengo un conjunto de principios morales que me explican y justifican de manera incompatible el hecho de si está bien o mal quemar a un gato (Harman, 1983) ¿es la observación el criterio decisivo para determinar cuál principio es el "correcto"? Amaya ahora tendría que dar un golpe de timón y decirme que no, dado su apego a artefactos como el del "equilibrio reflexivo" 5 que tiene, a diferencia de sus mentados "requisitos de observación", más coherencia con sus tesis sobre la coherencia. De lo que se trataría, replicaría Amaya, es de lograr un reajuste mutuo entre nuestras

\footnotetext{
5 Aquí hay un problema adicional, casi exegético, para comprender los compromisos de Amaya, ya que ella menciona la idea de "equilibrio reflexivo" de Rawls pero más tarde a Richardson que tiene una idea, algo distinta de la de Rawls. Richardson habla de equilibrio reflexivo "ampliado" para sugerir que incorpora "emociones" a la red que Rawls no está dispuesto a incorporar.
} 
convicciones "bien consideradas" y nuestros principios morales (y aquí no habrá orden lexical): a veces triunfarán unas, a veces los otros. Como sea: la pregunta por la confiabilidad sigue tan abierta como siempre y la sospecha de que los teóricos de la coherencia se ven empujados a trascender el marco puramente coherentista sigue vigente.

Sea como fuere, es usual leer que si los enunciados de una teoría coherente son verdaderos es porque probablemente existen verificadores $\mathrm{o}$, lisa y llanamente, un "mundo" que los hace verdaderos (Peczenik, 2000: 73). Los coherentistas, con todo, no quieren cumplir el dictum psicoanalítico de regreso a la matriz y hablan de una investigación paciente que a la larga lleve a converger en la verdad ( $a$ la Peirce), o de una "co-ducción" (algo así como inferencias convergentes) (Booth, 1988). Pero de nuevo: esta convergencia tocará la nariz del mundo y seguiremos en el mismo punto del principio.

Una quizás única manera de contestar estos atrevimientos para con la Profesora Amaya, que me permito realizar en nombre de un hipotético lector, sería reforzar la versión germano-idealista del coherentismo a la Berkeley o de una armonía progresiva a la Hegel. En estas versiones el mundo es chupado por la estructura de una mentalidad absoluta: Dios, el espíritu objetivo, etc. Pero, ¿sería útil para Amaya descansar su cabeza en estos idealismos? Tal vez sí, tal vez no. Del lado del sí estaría la idea conocida de que, por ejemplo, nuestros sistemas jurídicos continentales son originados en buena medida por "legisladores" a los que, por razones largamente explicadas en historia jurídica, se les han extrapolado tácitamente, al menos desde el iusnaturalismo racionalista a esta parte, facultades teológicas de ominisciencia, ominipotencia y, naturalmente, coherencia y completitud (al final del artículo retorno a este tema). Aceptar esta versión, empero, tendría un alto costo consistente en cómo digerir esta pesada metafísica y contrastarla luego con la desilusionante versión carnal y real de nuestros legisladores. Dicho lo cual, habría que agregar el conocido dato de que los sistemas jurídicos son un precipitado de diferentes capas superpuestas de ideologías y normas muy diferentes difícilmente coherentes en términos globales (Ratti, 2007). Es posiblemente por este motivo que Amaya defiende que la lanza de la coherencia es la "interpretación" que debe activarse para "coherentizar" aquello que no 
es per se coherente. No es que un sistema jurídico sea necesariamente coherente sino que en todo caso tal coherencia es producto de la interpretación.

4. La memoria de Amaya defiende 10 tesis sobre la coherencia para el razonamiento "jurídico" y, además, sostiene que adecuados filtros (llamémosles "dimensión institucional" del Derecho) rechazarán en el sistema (entre otros argumentos supongo que por introducir "incoherencia) principios morales "insostenibles". Ahora bien, se echa en falta que Amaya no brinde ejemplos al respecto, pero a fin de cuentas esto es sólo una instancia minúscula de las preguntas que me atrevería a formularle. Cuando habla de coherencia ¿es sólo entonces para el razonamiento "jurídico"? (Véase Schauer, 2009). Para auscultar parte del sentido de esta pregunta tomemos en cuenta un material como el del Derecho Constitucional integrado por principios que yo llamaría "bisagra", por amalgamar moral y Derecho, en el sentido que estos así llamados "principios" incluyen valores morales (dignidad, libertad, igualdad) que luego son formulizados con reglas jurídicas abstractas que establecen facultamientos, obligaciones, prohibiciones, etc. Con esta caracterización general en la mano, si uno además observa el tipo de conflictos de principios, a veces "trágicos" (Eskridge y Levinson, 1998; Zucca, 2007a; Lariguet, 2008; Lariguet y Martínez, 2008; Martínez, 2007), que se plantean en los tribunales, ¿no necesitaríamos algo más que una teoría de la coherencia del razonamiento "jurídico"? ¿Qué sucede si moldeamos la coherencia en términos de una teoría adecuadamente amplia, una teoría del razonamiento práctico por ejemplo al estilo de la sustentada por Joseph Raz? Como sabemos, Joseph Raz (2009: 166-181;182-202) ha sostenido entre otras cosas que: i) si el Derecho no es moral, nada lo es; ii) que los jueces son per se agentes morales y que por esto mismo aplican leyes morales a sus casos; iii) que la pregunta central no es qué lugar ocupe la moral en el Derecho sino qué lugar deba ocupar el Derecho dentro de la moral (¡no estamos ya lejos de Alexy aquí!); iv) que el razonamiento propiamente jurídico requiere una equilibrada ponderación de cuándo respetar la continuidad del Derecho (la mano ¿muerta del pasado?) y la innovación que a veces es requerida por casos que demuestran transformación social, cultural, 
tecnológica, moral, etc. Todo esto es una instancia muy general de algunas preguntas específicas que se me ocurren para Amaya y que espero sean de su agrado.

En primer lugar, ¿contempla su teoría de la coherencia estas complejidades a mi juicio centrales para cualquier propuesta de la coherencia en el "Derecho"6? Pongo entrecomillada la expresión porque sugiero que decir "Derecho" es cuestión más bien de acento, pues luego será inevitable que no quede clausurada la cuestión de la coherencia o incoherencia del Derecho con la moralidad (dejo a un lado a la política para no complicar más el asunto). Yo creo que la respuesta de Amaya sería que ella sí considera que estas complejidades deben inevitablemente ser consideradas. Esto es así, precisamente, porque en varios tramos de su trabajo ella habla de moralidad, principios morales y particularmente de "fines" (valores) que pueden entrar en conflicto. Ahora bien, con una pequeñísima gota de decepción no advierto en su memoria un trabajo más a fondo sobre la coherencia en el marco del razonamiento práctico, ni ejemplos concretos de conflictos entre valores en el propio ámbito del Derecho (por caso constitucional) ni entre valores bisagra del Derecho y valores de la moralidad en sentido más amplio y crítico.

\footnotetext{
${ }^{6}$ Son centrales entre otros motivos por la cuestión primordial del conflicto: cuando hay conflicto entre creencias o principios de un mismo dominio (conflicto intrasistemático) o cuando hay conflicto entre creencias o principios de distintos dominios aplicables a un caso, tal como suele pasar en conflagraciones entre moral y Derecho, (conflicto intersistemático), saber cuál es la versión del razonamiento práctico (qué tipo de idea de unidad o fragmentación del mismo se tiene) es vital para analizar la relación entre coherencia y conflicto: sea de creencias o normativo (referido a acciones). La teoría del razonamiento práctico preferida afectará la mirada sobre el conflicto y el modo en que se organizará la coherencia: ¿habrá principios todos al mismo nivel, habrá principios más básicos? Y esta pregunta, a su vez, impacta en la pregunta por el tipo de implicación en danza: si una que es estrictamente mutua (por referirse a principios del "mismo nivel") o una "jerarquizada" (por referir a principios de "distinto nivel). Pero en caso que sean principios de distinto nivel, donde hay unos básicos o fundamentales, ¿no colapsa el modelo coherentista en un modelo subrepticiamente fundacionista? ¿Cuál es el enfoque de Amaya a este importante respecto?
} 
En segundo lugar, me interesaría saber si, a la hora de reflexionar sobre la coherencia ya propiamente "jurídica" (sea lo que esto sea que signifique), Amaya ha pensado en el problema de la "autonomía" de ramas jurídicas (Lariguet, 2007a). Es verdad que un ideal de los juristas es pensar en la "unidad" del derecho (justamente ésta es una de las características de la coherencia); la unidad en diversos sentidos (unidad de principios, unidad de significados, etc.), pero es innegable que en nuestros sistemas jurídicos, al menos en los continentales, no suele verificarse "constancia semántica" (pues los mismos términos significan cosas diferentes en muchas ramas) y tampoco suele haber "constancia valorativa" (ya que cada rama pone el acento en valores que a veces están en pugna con valores de otras ramas). Este dato, suficientemente extendido en la dogmática jurídica y en la jurisprudencia, y poco estudiado por teoría del derecho, nos ha cegado sobre la presencia real de interesantes y recurrentes casos de genuino conflicto entre normas, principios, valores, conceptos normativos, etc., donde los jueces están auténticamente indecisos respecto de qué sub-sistema normativo aplicar a un mismo caso. Demostración de su indecisión son preguntas como éstas: ¿Es éste un caso de derecho aeronáutico o civil? ¿Es éste un caso de derecho laboral o civil? Tales preguntas suelen ser respondidas en forma incompatible y el ideal de unidad (poco revisado en sus múltiples dimensiones teóricas y prácticas) cumple un papel algo vaporoso. Pero, lo que es más importante todavía es que existen incoherencias en el Derecho producidas como consecuencia del relevante papel de estas ideas poco atendidas de autonomía de ramas jurídicas y unidad del Derecho.

5. La coherencia, como ya he indicado, supone que los elementos de cierto conjunto se apoyan mutuamente. Esta es una definición que Amaya suscribe sin reservas. Ahora bien, ¿qué significa pensar en que un conjunto variopinto de elementos se apoyen mutuamente reforzando entre otras cosas su inteligibilidad? Amaya sostiene que la coherencia tiene que mostrar la satisfacción de diversas restricciones empíricas, epistémicas, etc. Este tipo de restricciones, desde el punto de vista empírico, podrían ayudarnos a determinar que nuestra creencia acerca de si, cuando le damos la espalda a los árboles, 
estos cuchichean y ríen entre dientes a nuestras espaldas (Wisdom, 1986: 428), no es más que una duda expresiva de una ficción (aunque los árboles a veces sean la transposición de personas reales). Se trataría de una ficción porque activamos estas restricciones que son, por ejemplo aquí, ciertas leyes empíricas acerca de qué son los arboles iy lo que cabe esperar de ellos! Seguramente, en el campo de las normas, sea en el campo ético, jurídico o político, estas restricciones estarán fundadas en las mismas normas con independencia de cuál sea el 'status' que les concedamos a éstas ${ }^{7}$. Vuelvo a mi interrogante: ¿qué significa que unos principios se apoyen mutuamente? El candidato más fuerte para responder esta pregunta sería decir que "apoyo mutuo" equivale a "implicación mutua" 8

Ahora bien, demos por descontado que un conjunto cualquiera de principios antes de ser coherente debe ser consistente. La consistencia es una condición necesaria, aunque no suficiente dirán los teóricos de la coherencia ${ }^{9}$. Pero en el marco de la lógica clásica (dejo a un lado las

\footnotetext{
${ }^{7}$ Pues no olvidemos que, para algunos, las normas no pasan de ser algo similar a reglas de tanteo, tal como funcionan ciertas generalizaciones empíricas.

${ }^{8}$ ¡Pero atención! Véase nota a pie de página 97 en este mismo texto.

${ }^{9}$ Detrás de esta afirmación hay un punto profundamente difícil de examinar filosóficamente. La idea según la cual la coherencia es "más amplia" que la consistencia -idea que explico en el cuerpo del texto- produce un genuino enigma en cuanto a cuál debería ser la mejor forma de representar el nexo entre consistencia y coherencia. Por razones de simplicidad, en mi texto parto de la versión estándar, con arreglo a la cual, la coherencia siempre debe presuponer consistencia. No obstante, quizás este juicio debería ser rumiado con más detenimiento. Diversos coherentistas, a la Raz, han sostenido que una manera de mantener reforzada la red de coherencias, y de preservar las creencias más básicas para nuestras vidas, podría exigir ¿racionalmente? rechazar algunas consecuencias que se deducen válidamente de ciertas creencias de partida. Porque aceptar estas consecuencias podría hacer trastabillar la estabilidad de la red o trastocar severamente las creencias más básicas o importantes. Esto podría ser peligroso si nuestras creencias básicas son dañinas para nosotros $u$ otras personas y por esto, lo que más adelante llamaré un "discreto encanto de la incoherencia", podría ser un remedio para esta presunta enfermedad. Ahora bien, Bernard Williams (2002: capítulo 8) compara las concepciones de la verdad en Rousseau y Diderot. Dicha comparación es relevante, entre otras
} 
complicaciones que podrían introducir al análisis versiones no monotónicas, fuzzy y paraconsistentes) sabemos que la consistencia es una relación de "implicación lógica". Mientras el modus tollendo tollens es una relación de implicación que preserva consistencia, la afirmación del consecuente no lo hace. ¿Este tipo de implicaciones lógicas que

cosas, porque no hay que olvidar el eslabón problemático que existe entre coherencia y verdad. Pues bien, Williams sostiene que para Rousseau, para ser una persona "confiable" (término clave para Amaya), una persona debe ser sincera para con los demás y para consigo misma (tal como Rousseau intenta con sus Confesiones y como Grice o Habermas insistirán luego). Clancy Martin (2003) describe mejor que yo el problema que hay aquí. Citaré la reflexión que hace Martin en su reseña del libro de Williams. Dice: “This, Williams thinks, gives us a distorted view of the self, by assuming a transparency of consciousness that simply does not exist. The better account of selfhood is given by Rousseau's contemporary and sometime friend Diderot, who (like Nietzsche and Freud after him) describes coming to know oneself as a difficult, lifelong project of self-creation and stabilization. The self as it is given to us "is awash with many images, many excitements, merging fears and fantasies that dissolve into one another" (195), and the attempt to sort through and manage that refractory collection is the struggle for authenticity. Williams goes on to give his own (unfortunately, brief) account of authenticity, both before oneself and with one's community, in terms of "beliefs ... which [an agent] is committed to holding true in the context of his deliberation" (196). Here he provocatively argues that the many different forms of "wishful thinking" are not (as is often thought) impediments to the creation of an authentic self, but essential to the process of "individual deliberation" that alone allows such a self to develop". Adviértase la importancia que tiene para Diderot (y Williams) que conocerse no es tanto descubrirme como una entidad nouménica (el aire kantiano sopla aquí) sino que importa verme como un proyecto a largo plazo de "auto creación" y "estabilización" (este último término también es clave para la coherencia según Amaya). La relevancia de este proyecto es hacerme un sujeto que no sólo confía en sí mismo sino también en la comunidad (de nuevo brilla el interés de Amaya por estos temas). Pero he aquí que ciertas formas de "pensamiento desiderativo" (wishful thinking) "no son -como comúnmente se sostiene- "impedimentos" para llevar una vida auténtica" (agréguese confiable y estable). El delicado balance del pensamiento para calibrar cuánto de irracional hay en esta manera de abordar la coherencia o cuánto de racional, es un punto que retomaré en el texto, más adelante cuando me ocupe de un trabajo central de Donald Davidson. 
preservan o no la consistencia es igual a la implicación en la que piensan los teóricos de la coherencia? No sé qué pensará Amaya al respecto, me gustaría saberlo, pero por lo pronto diría que la respuesta sería negativa ${ }^{10}$. Digamos primero que todo, que los defensores de la coherencia piensan en un ensamblaje de piezas que consideran especialmente diferenciables de reglas al estilo "todo-nada" y por esto no es casual que obsesivamente refieran a "principios". Ronald Dworkin (1986: capítulos 6 y 7) particularmente ha sostenido que importa que las derivaciones de los principios que rijan un caso se obtengan de un conjunto coherente de principios tal que el ideal de integridad sea factible. Además, a nivel "global", a Dworkin le importa resaltar, dentro de su modelo constructivo $^{11}$ (Pereira, 2004: capítulo 1), la existencia de un Derecho que satisfaga el ideal de integridad; ideal que es parasitario de un conjunto de principios que, con diversos grados de abstracción (Lariguet, 2007a: capítulo 5), deben ser coherentes. "Coherentes" aquí entonces significaría que estos principios obtengan parte de su fuerza del apoyo que reciben, pero fuerza que también dan a estos otros principios de los cuales se "implican". En breve: la implicación no parece linear sino mutua u holística ${ }^{12} \mathrm{y}$, además y fundamentalmente, no parece ser estrictamente LóGICA. Es algo dudoso que lo que se tenga en mente aquí sea la implicación "deductiva" pura pues, si así fuera, volveríamos a la madriguera de la consistencia y habríamos perdido la buscada peculiar importancia de la coherencia para nuestros sistemas normativos. Es por este motivo que autores como Pablo Navarro (2003) o Riccardo Guastini (1999: véase "Principios en el Derecho Positivo) han propuesto que aquí

\footnotetext{
${ }^{10}$ No es por esto casualidad que Fred Will (1988), un defensor de un modelo coherentista no muy diferente del de Richardson, tan querido por Amaya, titule a su obra principal en este terreno como "Beyond Deduction".

${ }^{11}$ No discuto aquí si este modelo es compatible con la tesis dworkiniana que acepta hechos morales independientes de nuestras prácticas.

${ }^{12}$ Pero un problema diferente sería pensar en un modelo de coherencia donde haya principios más básicos de los que se deriven otros (véase nota a pie de página 97 ¡por favor!). Pero este rasgo básico haría que tales principios últimos no se impliquen a su vez de otros de modo tal de no caer en el regreso al infinito. Realmente tengo la intriga acerca de qué versión ofrece Amaya para evitar el problema del regressus ad infinitum y no caer, a su vez, en un fundacionismo.
} 
estamos frente a una denominada implicación "evaluativa". En mi opinión, el predicado "evaluativo" apunta a la clase de "material" en juego: valores, principios, fines. Sin embargo, sigo sobre ascuas con respecto al status de la implicación o la inferencia misma de estos valores o fines. La respuesta de Amaya tendría que ser, ha sido, que se trata de una implicación que es equivalente con una inferencia a la "mejor explicación" (y añadamos por mor de sus intereses, a la mejor "justificación”) del Derecho como un todo o, más humildemente, de un sector del Derecho. Pero como es una "inferencia" a la mejor explicación, y la misma a mi modo de ver es más abductiva o inductiva, pero no deductiva, puede que Amaya tenga que tomarse en serio "contra ejemplos" cruciales que podrían poner en aprietos el modelo de coherencia que se haya logrado hasta cierto momento. La inferencia a la mejor explicación-justificación no es, por lo tanto, un "cheque en blanco". ¿Está de acuerdo Amaya? ¿Qué consecuencias extrae de mi afirmación?

Como quiera que sea, no resulta un hecho insólito que varios esquemas de coherencia sobre el mismo conjunto de principios, presenten hipótesis de explicación y justificación incompatibles (Hart, 2001: 136; Aarnio, 1990: 23-38). Algo así sentían, por ejemplo, los jueces antes y durante la guerra de secesión norteamericana: era posible construir esquemas igualmente coherentes que justificaran la propiedad de esclavos o que no lo hicieran. Pero "justificación" (incluso en condiciones ideales de asertabilidad justificada como han dicho autores como Putnam) no parece calmar nuestra necesidad de distinguir la justificación, de la verdad. Aunque la coherencia tiene ciertos aguafuertes antirrealistas, quisiéramos pensar que hay un elemento realista o no coherentista (Kress, 2005: 537) que nos permita decir cuál de las dos posturas (si la esclavista o la antiesclavista) es la verdadera o correcta moralmente. Y aquí va otro interrogante para Amaya: ¿está ella interesada en desentrelazar en su teoría de la coherencia, sí o no, la propiedad de "justificación" de la propiedad de "verdad"? Ella se contenta con recordarnos que esta relación es problemática, pero esta afirmación lejos de calmar la pregunta la incentiva más. Pongamos las cosas de otra manera. Supongamos que tenemos ante nuestras narices 
dos conjuntos coherentes (por tanto internamente justificados) pero que nos llevan a respuestas incompatibles. Amaya tendría que admitir, como lo hicieron Quine-Duhem para las teorías científicas en general, o por ejemplo Aarnio para el Derecho en particular, que ésta es una situación de indeterminación o sub-determinación. Tenemos, por ende, una suerte de impasse entre ambos conjuntos: ¿por cuál se puede decidir en forma no arbitraria o caprichosa? Dejemos a un lado la afirmación fuerte de Ronald Dworkin (1983: 486; Lariguet, 2006: 205-222.) según la cual éstas serían situaciones "raras" en sistemas 'desarrollados'. Todo lo que necesito es que estas situaciones sean modalmente posibles y el término "raro", por lo tanto, no quita mi necesidad del medio. ¿Cómo elegiría Amaya estos conjuntos, sobre la base de qué metacriterio? Supóngase que, como Kress (2005: 538), alentáramos la participación de un principio moral que oficiara de "tie breaker"13, pero que este principio fuera manifiestamente incompatible con la autoridad del Derecho. ¿Qué diría Amaya en este caso?

Habría ejemplos más abstractos pero no menos reales de pensar el ideal de coherencia. Bastaría señalar que el Derecho podría ser interpretado en esquemas coherentes por corrientes tan diversas como la "feminist jurisprudence", la "jurisprudencia formalista", el "realismo jurídico" (norteamericano, escandinavo y también italiano), la "jurisprudencia marxista", las viejas corrientes de la jurisprudencia de "conceptos" e "intereses" o la "escuela libre de Derecho", los amigos del "uso alternativo del Derecho", los "garantistas", y un largo etcétera hacia atrás y hacia adelante para pensar que habría tantas estructuras coherentes de un mismo Derecho como corrientes rivales en disputa. Pero apenas quiero mencionar este hecho y más bien quiero proponer un experimento mental distinto que no hable de concepciones del Derecho en "pugilato" y tampoco, como en el ejemplo anterior, de un caso que ponga en tensión la llamada "autoridad" del Derecho.

${ }^{13}$ Dejo a un lado el posible problema de que tal principio formara parte de un complejo sistema también indeterminado por factores tales como el desacuerdo moral debido a la presencia de principios pertenecientes a otros sistemas o debido a la existencia de interpretaciones rivales de los mismos principios. 
Supongamos que dos valores o fines que forman parte del Derecho pueden formar redes coherentes pero que estas redes (grandes o pequeñas dependiendo del caso) resultan o bien simétricas o bien son fuertemente inconmensurables (Chang, 1997: Introduction). Imaginemos que la Sra. Evans ha buscado con su esposo tener un hijo mediante el sistema de implante de óvulos fertilizados en su matriz (Zucca, 2007a). Lograda la fertilización, se descubre que la Sra. Evans tiene tumores pre-cancerígenos, razón por la cual se frena la inseminación pero el óvulo fertilizado con semen de su marido es puesto a resguardo en un banco especializado. Removida la enfermedad, Evans vuelve a la carga pero he aquí que ya está divorciada. Empero, ella reclama su "derecho" a la inseminación, mientras que su "ex" ostenta el derecho a negar tal cosa y exige -muestra el derecho a hacerlo- de que se destruya el óvulo fertilizado. Supongamos ahora que los jueces se encuentran perplejos (y es verdad que lo estuvieron ya que el caso es tan real, diría Moore, como el hecho de que tengo dos manos). Su perplejidad emana del hecho de que pueden encontrar en los ordenamientos normativos pertinentes esquemas igualmente coherentes y apremiantes para tomar decisiones contrarias: apoyando a Evans o apoyando la pretensión de su "ex". Los jueces angustiados acudieron a lo que autores como Hampshire (2000) llaman la necesidad de una emoción empática, es decir, una emoción que nos lleva a "ponernos en los zapatos" o "en los tacones", según el caso, de las partes. Pero esta emoción ¿satisface los ideales de integridad, imparcialidad e igualdad que justamente se buscan con la coherencia y de los cuales ella obtiene parte de su point valorativo ${ }^{14}$ ? Aunque más adelante diré algo más (¡sólo algo!) sobre este punto de las emociones, contemos al público interesado que en el final de la historia los jueces fueron empáticos con "él" pero no con ella, con lo cual el clamor de guerra del feminismo todavía resuena en Europa y llega, algo rebajado, a nuestros machistas países.

\footnotetext{
${ }^{14}$ También Amaya cree que el "valor" de la coherencia es multifocal: apoya la coordinación social, la estabilidad de cierto orden social, facilita la realización eficiente de fines, coadyuva a la seguridad jurídica, etc. Luego en el texto, especialmente al final, diré algo sobre lo que presumiblemente podría involucrar esta versión del valor de la coherencia.
} 
Luego añadamos lo más indiscutible: la falta de acuerdo teórico entre los filósofos acerca de si esta empatía es lo mejor que tenemos en nuestro arsenal bélico para conflictos recalcitrantes ${ }^{15}$. Así, si los mencionados jueces vieron con simpatía utilizar algo que "presuntamente" no estaba en los esquemas coherentes ${ }^{16}$, para resolver la indeterminación, y Hamphsire (2000: capítulo 1) diría que es una movida aceptable hacerlo, autores como Raz (2009: 369) alegarían que, ante todo, es mejor una decisión más "distanciada", una que confíe en la labor "teórica" de la doctrina o dogmática jurídica a fin de quebrar el impasse y no una basada en emociones empáticas. Pace Raz, yo creo que la dogmática se encontraría frente al mismo callejón sin salida que los jueces, en tanto la situación sea realmente de indeterminación. Una manera diferente de comprender la propuesta de Amaya sería pensar en un ejemplo que no sólo contuviera indeterminación en el sentido antes expuesto sino que tuviera un aguijón "trágico" en el siguiente sentido: no importa lo que hagan los jueces: habrá un mal ontológicamente inescapable (Lariguet, 2008 y Lariguet, 2009a). Conjetúrese que la respuesta de Amaya fuera la siguiente: "pues bueno, busquemos un esquema de coherencia donde los principios en competencia hagan ajuste con el "mal menor"'. Ok. Pensemos en el caso del terrorista que ha puesto una bomba letal en $\mathrm{DF}^{17}$ y no se aviene a decir dónde se localiza la bomba. El tiempo corre. No hay tiempo real para evacuar más que al diez por ciento de toda la población presente en dicha ciudad. Construyamos dos esquemas igualmente coherentes sobre un hipotético Derecho. El esquema 1, utilitarista, o instrumentalista en el vocabulario de Amaya, dirá que torturarlo es el "mal menor", ya que esto nos permitirá salvar el 90 por ciento de gente que será destruida por la bomba. El esquema 2,

${ }^{15}$ Un síntoma de duda es precisamente la necesidad de apelar (Elster, 1995: 9) a la "moneda" como criterio que garantice no sólo quebrar el impasse sino de hacerlo imparcialmente. Coincido con Bagnoli (2006: 1-14) en que este criterio del azar es puramente formal. No resuelve el problema sustantivo de qué opción es la que merecería llevarse el crédito.

${ }^{16}$ Alguien puede decir que las emociones están en estos esquemas, por lo menos algunas que se consideren apropiadas. Véase infra nota a pie de página 128.

${ }^{17}$ En mi ciudad los empleados municipales ponen pequeñas bombas casi todos los días, pero no discutiré esta cuestión vernácula. 
deontologista, dirá que torturarlo es un mal "mayor": el sacrificio de uno no es comparable con el de miles o millones y no es cierto que valga más no rasguñarme el dedo mientras el mundo perece. Sea como fuere, habrá un mal inescapable y no parece haber algo así como la teoría moral unívoca sino varias competitivas. ¿Hay un criterio metaético neutral para decidir entre ellas que no sea arbitrario y que evite dar una "ramita" de olivo a los critical legal scholarships? Parece que estamos bordeando los "límites" de la coherencia y me pregunto cuáles son los que admite Amaya y si ella estaría dispuesta a condimentar su teoría con ingredientes realistas que la forzaran a aceptar que estos esquemas deben ser trascendidos para obtener respuestas; respuestas que irremediablemente pueden ser arbitrarias. La coherencia es parte de la historia: no es garantía en oro de que saldremos airosos siempre.

6. En el marco de mi afirmación anterior, creo que cuando Amaya sugiere que es mentira, ¡como muchos dicen! que la teoría de la coherencia "elimine" todos los conflictos, reconoce la existencia de una afirmación frecuente. Pero, sin embargo, cuando nos detenemos en su tesis cognitiva o psicológica según la cual hay una disposición a la armonía (dígase COHERENCIA) su reconocimiento parece diluirse. Voy a deshacerme de la cuestión de las disposiciones o tendencias que ya son lo suficientemente problemáticas en sí mismas para filósofos no seducidos por formas de naturalismo fuerte. Más bien, bastaría empezar a señalar que para las teorías psicoanalíticas (porque es desde el punto de vista psicológico que estamos conversando ahora con Amaya), estas tendencias (o "presiones por la coherencia", como ha dicho Nagel) pueden a veces ser falsificadoras. En realidad, disponemos de innumerables mecanismos, estudiados por Freud, Klein, Lacan, (Alford, 1992) que indican cómo revertimos, como en un espejo, la realidad y llegamos a ver un escenario, por ejemplo el personal, como coherente, cuando en rigor, conforme nuestra psicología profunda, no es el caso.

Amaya, recordemos, hace depender buena parte de la coherencia de la interpretación. Por ende, habría que discernir el Derecho como "objeto" coherente o incoherente, de los "sujetos" que, mediante su interpretación, lo "muestran" o lo "construyen" como 
coherente. Dejaré a un lado todos los problemas que ya quedan sugeridos al usar palabras como "mostrar" y "construir" y tampoco me meteré con la cuestión de cómo pensar la objetividad de la interpretación y qué objetividad nos quedaría plausiblemente cerca: si una realista, si una caritativista, etc. Quiero centrarme, más bien, en los agentes que quieren "interpretar" a un conjunto normativo (ético, jurídico, político) como "coherente". Este aspecto es significativo porque Amaya expresa con energía que ella busca algo así como una "jurisprudencia de sujetos". No hay que mirar tanto a las normas como a los sujetos que operan con normas. Pero emerge aquí la vieja pregunta: ¿quién vigila a los vigilantes, en este caso de la coherencia? (Véase nota a pie 3 de este trabajo). Me temo que sería promisorio que Amaya se ocupara de la coherencia de los ipropios agentes intérpretes! Veamos porqué hago uso de los signos de admiración en este caso.

Uno de los filósofos que nos han cautivado con su análisis de las "paradojas de la irracionalidad práctica" ha sido Donald Davidson (1981), ampliamente influido por la teoría freudiana. La paradoja, según Davidson, estriba en que existen casos de irracionalidad práctica de agentes (patentizados en conflictos de creencia y acción) donde se conjugan dos aspectos difícilmente conciliables: intención e irracionalidad. Bajo el "esquema platónico" esto es un imposible conceptual: nadie puede querer el mal para otros o para sí mismo intencionalmente a menos que esté domeñado por pasiones como las de Fedra que ruega a su sangre no borbotear de amor por Hipólito o Medea que le pide a su mano no asesinar a sus hijos. Estos casos de voluntad dominada no interesan a Davidson centralmente. Su interés primordial estriba en casos donde el agente escoge el peor plan intencionalmente. Davidson (1981: 8) dice: "Pensándolo bien, resulta obvio que ni el principio medeico ni el análisis de Aristóteles (agreguemos nosotros Platón) admiten casos netos de conflicto, casos en que el agente tiene buenas razones, a la vez, para hacer y para omitir una conducta determinada o lo que es equivalente, tiene buenas razones para hacer dos cosas que se excluyen entre sî’. En forma más cualificada agrega: "lo que requiere explicación es la acción de un agente que habiendo sopesado las razones a favor y en contra, y habiendo juzgado que la preponderancia se halla de las razones de un lado, actúa luego 
contrariamente a su juicio" (p.8). Sin embargo, esto forma parte de los resortes íntimos del agente que, perfectamente, podría mostrarnos luego una baraja coherente de piezas normativas. ¿Pero qué pasa cuando varios agentes nos presentan barajas igualmente coherentes? ¿Nos importa indagar en su historia psicológica, tal como demandaban algunos realistas jurídicos? ¿Es ésta accesible? El problema está, de nuevo, en el CONFLICTO y qué papel jugaría la coherencia de agentes que pueden ser incoherentes. Davidson (p. 9) sostiene que "sólo hablamos de conflicto cuando los pro y los contra poseen gravitación y se aproximan a la situación de equilibrio" (de manera similar, Atienza, 1997: 15). La conclusión correcta de Davidson es que la "lógica no puede indicarme qué hacer" (véase también Alchourrón y Bulygin, 1991: 303). Pero si la lógica no puede, ¿puede la coherencia? La respuesta a esta pregunta corre por un risco dificultoso, no siempre advertido por los amigos de la coherencia que buscan en la misma un complemento argumentativo de la lógica que conduciría en una casi segura "respuesta correcta siempre". (por ejemplo, McCormick, 2005, quien habla de la figura ideal del juez como si fuese un "King Salomon" para resolver correctamente todos los casos; es una figura similar al Hércules de R. Dworkin y al Arcángel de R. Hare). Nadie mejor que Davidson para mostrar los riesgos de una respuesta afirmativa o negativa rotunda. Sostiene Davidson (1981: 16): "La paradoja que subyace a la irracionalidad, que ninguna ${ }^{18}$ teoría puede eludir del todo es ésta: si la explicamos demasiado bien la convertimos en una forma encubierta de racionalidad; mientras que si atribuimos incoherencia con ligereza, debilitamos nuestra aptitud para diagnosticar la irracionalidad al suprimir el trasfondo de racionalidad necesario para justificar todo diagnóstico".

7. Al problema de la irracionalidad práctica y el conflicto que presenté, se suma la introducción, por parte de Amaya, de una concepción "neoaristotélica" (véase, por ejemplo, para el campo ético Nussbaum, 2009; Hurtshouse, 2001; para el campo de ética y teoría del conocimiento, Zagzebski, 1996; para el campo judicial, Sollum-Farelly, 2008). La introducción que hace Amaya de esta concepción es

${ }^{18}$ La cursiva es mía.

108 - Revista Discusiones X 
importante. Ya hemos visto que Aristóteles, antes Platón, tienen formas de pensar que, a la larga, logran un efecto de cuasi prestigiditación: los conflictos terminan, lentamente, evanesciéndose.

En otros trabajos, Amaya (2008a y 2008b) ha mostrado un -ijuvenil fanatismo?- por las llamadas "teorías de la virtud" que pueden remontarse a Aristóteles. En particular, Amaya se siente cerca de autoras como Hurtshouse y Zagzebski que son teóricas de la virtud que deben ser imaginadas como soldados cubiertos de pesados metales. Según mi entender, estas autoras, al igual que Geach y Anscombe, sostienen un "teísmo" subyacente según el cual hay algo en el mundo (finalmente es Dios) que permite que siempre la "armonía" quede preservada o pueda ser "restaurada". El sucedáneo para Dios será el hombre virtuoso, para los éticos cristianos (Rae, 1995), el "santo"; en el caso jurídico, un juez virtuoso y por esto es que Amaya se siente tan atraída por la "ética judicial" sobre la base de una ética "aretaica" o de virtudes. Apartaré los problemas jurídicos, políticos y éticos ${ }^{19}$ que podrían desprenderse de

${ }^{19}$ Desde el punto de vista particularmente ético, estos problemas, en mi opinión, son cuatro y se pueden denominar como: a) el problema de la "sospecha". Según Rochefoucauld (véase Elster, 2002: 122) todo hombre es un bellaco y las virtudes aparentes ocultan una realidad fraudulenta; b) el segundo problema lo llamaría, como Montaigne, el problema de la "incertidumbre de la virtud": ¿Cómo saber si lo que un agente hace lo hace por virtud o para impresionarnos como tal? (Elster, 2002: 123); c) el tercer problema lo llamaría como el problema del presupuesto teístico según el cual la incoherencia, el mal, el conflicto, surgen por un mundo sin Dios (como declaró Nietzsche o sugirió Dostoievsky); pero si en el mundo hay un Dios, un virtuoso o un agente racionalmente comprometido con normas deónticas sustanciales, entonces no puede haber nunca incoherencia, mal o conflicto. Este presupuesto fue formulado magistralmente por Maeterlinck cuando sostuvo que hay conflictos trágicos porque "no estaba un sabio cerca" (véase Scheler, 1961: 146); d) el cuarto problema es la presuposición de unidad de las virtudes (teoréticas y prácticas); unidad lograda mediante la soldadura que produce la frónesis. Si la frónesis se activa, la idea es que todo conflicto será, a fin de cuentas, aparente. Pero como Madame de Stäel sostuvo en forma desafiante: "si yo me llamara Tell no sería prudente" (Scheler, 1961: 155). El desafío indica que deberíamos ser algo más humildes o menos fanáticos y pensar que a veces ser valiente puede estar en conflicto con ser prudente y es justamente que, cuando 
juzgar las virtudes o vicios de los jueces (véase, por ejemplo, Malem, 2001: 379-403). Quiero concentrarme en todo caso en la triple estrategia de teorías de la virtud, centradas en agentes. La primera estrategia consiste en postular que si un agente es virtuoso, por definición, no enfrentará conflictos o dilemas. Esto es correcto, primero por la definición misma de virtuoso: un virtuoso actúa característicamente de modo virtuoso ${ }^{20}$. Segundo, si se consideran los dilemas que surgen por conductas de los propios agentes habrá que señalar que, si son virtuosos, no pueden generarse encrucijadas morales. Con todo, esto es falso para los dilemas (generados por el "mundo" como han mostrado McConnell, 2002 y Blackburn, 1996: 127) que se le imponen coactivamente a un virtuoso. La segunda parte de la estrategia consistirá en señalar que ante estos casos, por ejemplo el famoso caso del tirano que trata Aristóteles en ética nicomaquea, el súbdito identificará su genuina obligación moral y no se "ensuciará las manos". Por ejemplo, acudirá al "autosacrificio" antes de hacer aquello moralmente reprochable que le ordena el tirano. Dejemos a un lado ahora el problema de si el autosacrificio, eventualmente correcto para un aristotélico, no violaría alguna norma moral más básica de autopreservarse, lexicalmente prioritaria a la de autosacrificarse.

La tercera parte de la estrategia será decir que, antes del sacrificio, si el virtuoso apela a esa rutilante meta-virtud que es la "frónesis" encontrará siempre -bueno, ¿digamos "casi siempre"?- la "respuesta correcta" para el caso de conflicto. Con seguridad que esta respuesta correcta se puede reconstruir en términos de escapar exitosamente entre los cuernos del dilema buscando una vía intermedia en que ningún valor sea violado y los valores rivales sean al menos parcialmente satisfechos. Finalmente, en caso que esta vía intermedia no sea lograda le quedará al virtuoso sentir pesar. Este sentimiento le permite al virtuoso echarse un manto protector frente a la mala suerte moral de no haber podido evitar hacer algo trágicamente malo; en otras

en ocasiones buscamos la virtud como un todo holísticamente coherente, más podemos estar alejándonos de ella.

${ }^{20}$ Dejemos a un costado la discusión sobre la circularidad definicional. 
palabras, le permitiría, se supone, seguir siendo virtuoso, mantener intacta su "identidad moral", mostrando deferencia con las normas morales correctas que no pudo satisfacer (una defensa de esta idea en Greenspan, 1995; una versión más crítica en Lariguet, 2009b).

Es a esta altura del match que mi pregunta para Amaya es la siguiente: ¿hasta qué punto se puede defender que una teoría de la coherencia, recargada de una teoría de la virtud basada en la mencionada triple estrategia, no elimine realmente el conflicto? Olvidémonos, si se prefiere, la historia personal de "encandilamiento" de Amaya por la teoría de la virtud. Cuando digo encandilamiento no quiero NEGAR virtudes en la teoría de la virtud. Creo que tiene Muchas, especialmente aquellas ligadas con la posibilidad de complementar una visión muy abstracta de las normas con una concepción más sensible a la percepción y al papel de las emociones, amén de una concepción de "regla" más "terrestre", no kantiana en sentido rigorista. Para la concepción aristotélica (o "neo" aristotélica) las reglas son sumarios de experiencias efectivamente aprendidas, pero no de todas las experiencias, ya que habrá experiencias futuras por aprender. Por lo tanto, para esta concepción, no habrá problemas en aceptar la existencia de aspectos del mundo no contemplados por las reglas; aspectos que serán mejor captados y tratados por una facultad como la frónesis o prudencia, debido a que es una facultad que, sin olvidar la importancia de las generalizaciones, está más cerca del suelo de los casos particulares con todas sus posibles novedades. Ahora bien, lo que sí me produce algo de molestia es adoptar esta teoría de una manera algo fundamentalista o pesada y no de una manera más ligera y fresca como en mi opinión uno puede encontrar en el trabajo de Martha Nussbaum, pero no en los de Hurtshouse o Zagzebski a quienes sigue Amaya. Pues bien, dejemos esta cuestión de gustos filosóficos aparte y centrémonos pura y exclusivamente en la idea de "coherencia". Ya hemos visto que la misma evoca la imagen de "apoyo mutuo" entre principios. Me gustaría mostrar ahora qué clase de "características" suelen acompañar -muy amigablemente- a la coherencia tal que la presencia e importancia del conflicto puede ser realmente eliminada. De acuerdo con Ken Kress (2005: 534), un 
sistema es "gradualmente" cada vez más coherente si va agrupando las siguientes características:

a) Consistencia: propiedad ya definida en páginas anteriores.

b) Comprehensividad: una teoría tiene esta propiedad si tiene respuestas, dentro de su esfera de aplicación, para todas las cuestiones, incluyendo la estipulación de que algunas cuestiones no tengan respuestas por parte de la teoría.

c) Completitud. Una teoría es completa si tiene "una" respuesta correcta para todas las cuestiones que caen dentro de su ámbito. Desde este punto de vista, no hay lagunas, no hay indeterminación y rige la bivalencia: es verdadero o falso que algo cae o no cae dentro de ese ámbito.

d) Monismo. Una teoría es monística si parte, finalmente, de un único principio maestro básico y abstracto.

e) Unidad. Una teoría es unitaria si demuestra tener relaciones internas de apoyo mutuo.

f) Articulabilidad. Una teoría tiene esta característica si dispone de métodos uniformes para resolver todas las cuestiones que se le presenten y esta resolución no depende de "intuiciones".

g) Justificado. Una teoría es justificada cuando resuelve los conflictos con "razones" que pueden remontarse a metaprincipios.

Seré previsible: empezaré por a), b) y c). Es interesante notar, ante todo, cómo lógicos deónticos, tildados a menudo de "positivistas jurídicos", como Alchourrón y Bulygin, sí están dispuestos a aceptar lagunas normativas allí donde los teóricos de la coherencia, por lo general auto embanderados bajo la etiqueta de "teoría de la argumentación", no lo hacen.

Digamos que a) no puede ser rechazada a riesgo de cometer una contradicción lógica ya que, por definición, antes de hablar de "coherencia", se debe presuponer la "consistencia", que sería la característica más importante e ineludible (véase, sin embargo, los matices de nota a pie 9 junto a mi tratamiento de Davidson en este texto). 
Admitamos, por mor del argumento, que aquí no hay grados. La consistencia tiene que estar detrás de la coherencia o no habría posibilidad de hablar de justificación, inteligibilidad, ni de nada. Pero b) y c) ya encierran una complejidad soterrada. Mientras b) apunta a la inclusión de todas las respuestas, incluyendo bajo qué condiciones no hay respuesta, c) apunta no a la "extensión" del ámbito de una teoría o sistema normativo sino a su falta de "lagunas". En algún sentido uno encuentra a b) reflejado en segmentos diversos del Derecho: por ejemplo, en el Derecho civil es común decir que, cuando hay indeterminación (no-respuesta), es "obligatorio rechazar la demanda", lo cual implica para autores como Atria (2005) y Ruiz Manero (2005) que no hay discreción (el primero de ellos), o directamente que no hay lagunas normativas (el segundo) ya que al menos hay "una norma" que "determina" qué hacer cuando el Derecho no tiene una respuesta específica.

Ahora bien, la idea de completitud comienza a tornar las cosas más problemáticas pues apunta justamente a la idea de que siempre hay respuesta correcta y se trata de una, no de varias en competencia. Dejaré de lado la importante discusión sobre si es factible distinguir lagunas "normativas" de "axiológicas" (por ejemplo, Caracciolo, 1994: 30; Rodríguez, 1999: 349-369) y tampoco hablaré de lagunas de "reconocimiento" activadas por variados fenómenos de vaguedad. Lo que me atrevo a preguntarle a Amaya es si su teoría de la coherencia, que sin duda abraza el rasgo a), también se compromete con b) y c). Si su respuesta es afirmativa, Amaya parece estar admitiendo que no existe para ella Ningún conflicto que sea irresoluble. No ve, ergo, ningún discreto encanto en admitir cierta incoherencia (ya hablaré de este "discreto encanto" luego).

Pasemos a d) (monismo) y e) (unidad). No hay dudas que no toda teoría coherentista necesitaría recurrir a d) y e); por consiguiente, tendríamos que meditar en la posibilidad de admitir también teorías coherentistas "pluralísticas". Ya el poeta Walt Whitman dijo que los jueces deberían ser los "estabilizadores de lo diverso" y esto podría lograrse, en efecto, mediante una estructura coherente. Sin embargo, 
diversos filósofos políticos nos han instalado la sospecha de que, detrás del discurso de la coherencia (y el consenso que viene detrás de la misma), hay un sutil y silencioso movimiento hacia la uniformización de valores y a situarnos cada vez más lejos del pluralismo ${ }^{21}$. No conozco cómo concibe este punto Amaya y tal vez sería importante tener su respuesta. Ya que, de nuevo, el pluralismo suele ser uno de los colegas del conflicto: mientras más valores diversos haya, más reales pueden ser los conflictos.

Tenemos, por último, a f) (articulabilidad) y g) (justificación). El abordaje más obvio para f) y g) sería pensar que Amaya debe dejar fuera de su propuesta a las "intuiciones", tal como intenta hacer un autor como Rawls con su idea de "equilibrio reflexivo". Un problema recorrido por la filosofía de la mente, es que las intuiciones, por lo general, no son fácil -o inmediatamente- reconducibles a fórmulas de contenido proposicional: son algo así como lo que los estoicos llamaban "impresiones catalépticas" y que uno encuentra en abundancia en una obra como la de Proust ${ }^{22}$. Por su parte, aquellas corrientes éticas que son reacias a aceptar alguna forma de intuicionismo, dirían que si nos guiamos por intuiciones perdemos un "método" para resolver los $\operatorname{conflictos}^{23}$ (de aquí la importancia de la articulabilidad para los coherentistas). Por último, a la Russell, se podría pensar de las intuiciones que ellas son algo así como "knowledge by acquintance" no

${ }^{21}$ Aquí vuelve a ser relevante la cuestión de la "génesis" o "inputs" que formarán la "base" de la teoría de la coherencia de Amaya, ya que podrían existir principios o valores o formas de vida no incluidos en una base y entonces se trataría de una coherencia pobre, poco extendida. Justamente, el ideal de la coherencia es lograr su máxima extensión (Peczenik, 2000: 67-68). Tampoco se ve en su texto qué base admitiría ella, por ejemplo, para el Derecho. Supongo que admitiría la legislación, la jurisprudencia, la doctrina, ¿pero qué tal con principios que nos parecen intachablemente morales pero contradicen criterios básicos de una regla de reconocimiento?

${ }^{22}$ Pensemos por ejemplo cuando el autor, al quitarse las botas en Balbec, tiene estas impresiones que le ayudan a descubrir el amor que sentía por ciertos seres queridos.

${ }^{23}$ Sobre estos métodos, diversos, como el equilibrio reflexivo, el orden lexicográfico, la "pre-emption" para diseños jurídicos federales, etc., véase Kress, 2005: 541-542. 
formulable proposicionalmente (véase Michelon, 2006). Voy a suponer, sólo por mor de la argumentación que estoy perfilando, que lo anterior es correcto, aun si estoy consciente que podría ser rebatido y que sería importante hacerlo pues el intuicionismo tiene un recorrido de mayor complejidad que merecería de nuestra parte una atención más seria. Más bien, quiero dirigir mi lente a la siguiente cuestión: cuán lejos quiere llegar Amaya con sus sugerencias, puntualmente, acerca de tener COHERENCIA MÁS TEORÍA ARISTOTÉLICA. Esta última suele hacer énfasis en el papel de percepciones con las que nos enfrentamos a ciertos casos, particularmente difíciles o trágicos, que nos conducen a una respuesta correcta (adiós conflicto irresoluble nuevamente). El punto es que estas percepciones, con las que nos enfrentamos, no son, al menos no en ese momento de enfrentamiento, piezas formulables proposicionalmente: se parecen más bien a las llamadas corazonadas de las que hablaban los "realistas jurídicos" cuando describían cómo se resolvían "realmente" los casos judiciales. Pero, si esto es así, la necesidad de articulabilidad sería puesta en cuestión por una aproximación ¿inconscientemente? intuicionista de Amaya. En todo caso, tenemos que saber qué es lo que ella está dispuesta a abrazar del aristotelismo; de todas maneras, por otros trabajos suyos, parece que sí tendría que aceptar al intuicionismo en el sentido antes referido. Por lo tanto, esta incorporación sí estaría en pugna con su enfoque coherentista. Una defensa de Amaya a mi ataque filosófico (éste es el momento para tomar tequila o ajenjo por ejemplo y donde el té ceilandés se deja pacientemente a un lado) sería por la vía del concepto de "responsabilidad epistémica". Un agente virtuoso no es cualquier tipo de agente: no muestra sólo apego a normas deónticas de heurística y justificación moral, jurídica o política sino que va más allá, exhibiendo cualidades aretaicas. Ahora bien, el concepto de responsabilidad epistémica enfrenta serios problemas que deben ser despejados antes. En primer lugar, si el perfil de tal responsabilidad es aretaico, y todavía no nos hemos planteado si existe la posibilidad de formular las cualidades aretaicas en reglas, me temo que tal responsabilidad tiene un componente posiblemente fiabilista. Digámoslo de esta forma: "Soy virtuoso, sé encontrarle la madeja a los hechos de un caso, desarmar incoherencias, pero no sabría bien cómo explicártelo". Simplemente lo hago así. "Qué se le va a hacer: soy un virtuoso". El 
fiabilismo no satisface la condición de articulabilidad. No es por ello irracional y por tanto no viola necesariamente la necesidad de justificación en forma contundente. Pero sí que es en todo caso arracional (Lariguet, 2007b) pues no forma parte de un aparato de enunciados explicitados, sino de un aparato con intuiciones que podrían explicarse a partir del funcionamiento de mecanismos "fiabilistas". Amaya podría replicar que muchos principios con los que operamos, por ejemplo en el Derecho son, de hecho, así, "implícitos" (por ejemplo, Dworkin, 1983; Tribe, 2008; Ernst, 1992). Con todo, para que la coherencia pueda operar como maquinaria, lo implícito debe ser hecho explícito (por ejemplo, Brandom, 1998; Harman, 2003) o, de lo contrario, lo implícito será "arenilla en la máquina". El segundo problema archiconocido es preguntarse hasta qué punto se le puede exigir a un agente Algo MÁs que su mero apego a normas deónticas. Pedirle, además de este apego, ser virtuoso ¿no es supererogatorio? Además, ¿no hay casos donde el agente "acierta" con sólo cumplir normas deónticas? Para hacer peor el caso: ¿no hay situaciones donde el agente acierta por pura "suerte epistémica"? No obstante, la suerte aludida es "de las buenas", ¿pero qué pasa cuando hay "mala suerte epistémica" y el agente ni siquiera acierta ${ }^{24}$ ? Esto último sería factible en el supuesto incoado por Gettier de que creemos estar justificados a creer que x (coherentemente) pero no sabemos que no es el caso pues hay factores que perturban la "verdad" de x y no nos damos cuenta, al menos prima facie, de estos factores. Es a la luz de estos argumentos que he sostenido que Amaya debería explicarnos si su teoría de la coherencia cubre sólo la justificación O SI TAMBIÉN CUBRE la verdad. Y si solo fuera la justificación, me temo que no podría evitar la batalla de fondo entre internalismo y externalismo en teoría del conocimiento que acabo de describir con la referencia a Gettier. Su teoría de la justificación inevitablemente tendría que colapsar en la discusión planteada por Gettier de que estamos justificados a creer que x, pero no es el caso. Pero si decimos que "no es el caso", ¿no hemos puesto el eslabón que vinculará justificación con VERDAD, sabiendo, OH VIDA COMPLEJA, que

\footnotetext{
${ }^{24}$ Esta pregunta es muy complicada. Afecta la consideración del agente como
} virtuoso. 
no puedo tener ambas en casos relevantes de conocimiento? Y, para complicar más las cosas, digamos que no es lo mismo decir "no es el caso" en ciencias puramente observacionales, que en ciencias basadas en enunciados prescriptivos donde queremos saber si es o no el caso que tenemos, por ejemplo, tales derechos o tales obligaciones.

8. Voy a decir algo ahora que puede sonar a "herejía": Alguna vez Putnam (referido por Nagel, 2000:27) ha hablado del "discreto encanto de la incoherencia". Creo que cuando se habla de "discreto" se está pensando en algo ya insinuado por la reflexión de Davidson que cité antes en cuanto al riesgo de "racionalizar" en exceso (como hacemos con nuestras propias fallas o incoherencias) nuestras vidas mentales y morales. Admitir cierta incoherencia es la posibilidad de admitir la existencia de conflictos, a veces IRRESOLUBLES, al menos para un cierto tiempo t, pero a veces en cualquier tiempo. El conflicto es un dato del mundo que siempre nos moviliza a la necesidad de transformaciones de sistemas o parcelas de sistemas y a mayor sensibilidad a la pluralidad o diversidad de creencias, mientras que la coherencia parece algo más cercano, en términos sociológicos, al funcionalismo de Sorokin o Parsons y no es casual que Amaya sitúe el valor de la coherencia en la estabilidad, la coordinación, etc. La coherencia es un mecanismo de ajuste conservador, pero a veces hace falta eso que Atienza (2008: Prólogo a Lariguet) llamó "conciencia trágica" para impulsar cambios más radicales que lleven de una situación injusta a una más justa, cambios que probablemente involucren sacrificar otros valores ${ }^{25}$. Probablemente, estos cambios presupondrán la posiblemente justificada activación de ciertas incoherencias.

9. Un último bocado sobre la "relación entre neoaristotelismo y coherentismo" en la propuesta de Amaya. Los aristotélicos (viejos y

${ }^{25}$ Precisamente, la idea de que a veces tenemos una poderosa y bien articulada justificación moral para dejar un valor a un lado, ha servido a Ronald Dworkin (2005: 105-116) para criticarle a Berlin su falta de perspicacia para defender que estamos condenados a ciertos, solo digo ciertos, conflictos trágicos. Dworkin cree que algunos de estos conflictos no serían trágicos si logramos articular la justificación que acabo de mencionar. 
nuevos) siempre han puesto de manifiesto dos cosas. Por un lado, la idea de que el virtuoso tenga una adecuada composición emocional (también los pragmatistas deweyanos como Lekan, 2003) tal que puedan resolver armónicamente conflictos. Por el otro, la idea de que este agente virtuoso tiene esas características que Walt Whitman (véase Nussbaum, 1995:80) puso en su "Phantom", a saber: i) un hombre ecuánime; ii) nada en él (sino fuera de él) es grotesco o excéntrico; iii) ve las cualidades de las cosas en su justa proporción; iv) es el árbitro de lo diverso; v) no es un argumentador sino un juzgador; vi) que no juzga como juzgan los jueces sino que es como el sol que ilumina las cosas.

Desde luego que no es éste el lugar para tratar con detalle la poesía de Whitman y su nexo con la concepción aristotélica del virtuoso. Tampoco para tratar con minuciosidad la teoría de la frónesis basada en una percepción "afinada" de las cosas (ver puntos iii) y v), referidos al Phantom, por ejemplo). Detengámonos en dos filamentos especialmente importantes. El primero es que el juzgador aristotélico "no juzga como los jueces": es como el sol que ilumina las cosas y no es un argumentador sino un juzgador. La metáfora del sol es radiantemente clara: habla de alguien con capacidad de percibir lo oculto de los casos, sus más mínimos detalles.

Hagamos el siguiente paso ahora: ¿Qué sucede con la otra idea de que no es un “arguer"? Whitman, como Aristóteles, no están pensando en que los jueces no tienen que dar razones. Esta no es la idea que subyace a decir que no son arguers. La cuestión, más bien, es que las razones pertinentes no revisten la forma, o no forman parte, de un engranaje deductivo que va desde principios más o menos abstractos y universales al caso particular. La idea es que los jueces atienden las "saliencias del caso" 26 y esto no me parece tan distinto de la idea de Amaya según la cual la coherencia es "contextual y relativa". De acuerdo, de acuerdo... Pero, ¿puede la teoría de Amaya ser hospitalaria, a la vez, de un modelo estándar de coherencia y de una teoría aristotélica apegada a contextos? ¿No hay aquí una tensión que resquebrajaría las paredes de su teoría? Mientras

${ }^{26}$ ¡El Kant de la Crítica del Juicio no está lejos de esta idea! 
cualquier modelo -por lo menos "estándar"- de coherencia apunta a los ideales de igualdad, generalidad o universalidad, integridad, estabilidad, y seguridad jurídica para el caso del Derecho, la teoría aristotélica presta atención a los casos particulares de un modo similar a lo que éticas a la Murdoch, o a la Nussbaum, llamarían la "loving attention" al caso particular. El modelo de la coherencia puja por obtener un punto de vista de imparcialidad o de "tercera persona", mientras que el modelo aristotélico es más devoto de un punto de vista de "primera persona". Mientras el modelo de la coherencia tiende al espacio de razones públicas $^{27}$, la concepción aristotélica de la percepción de particulares está más próxima a las relaciones personales (en esta línea, véase Michelon, 2006). Yo creo que Amaya no tiene que sentirse tironeada en direcciones contrarias y puede encontrar alternativas conciliatorias entre sus dos intereses: tener un modelo estándar de coherencia y defender una concepción neoaristotélica (habrá que ver con qué "scope"). Aunque pueda ser debatible, pienso que ella podría echar mano de estrategias como las siguientes.

Primero, delinear una figura de juez que no sea tan remotamente lejana del "judicious spectator" de Adam Smith, un autor que, como se sabe, no sólo se ocupó de economía sino justamente de elaborar una teoría de los "sentimientos morales". Según Nussbaum (1995: 72-73), este juez puede tener imparcialidad pues es "spectator" pero también puede exhibir "identificación empática" con los problemas de las partes $^{28}$, revelando una mirada atentísima a las minuciosidades

\footnotetext{
${ }^{27}$ No es extraño por esto que la teoría que defiende la percepción aristotélica para el ámbito público (por ejemplo la política), defendido por H. James en literatura, haya sido atacada por autores como los marxistas. Y recordemos, de paso, cómo la heroína del Cuaderno Dorado de Lessing es criticada por esta misma razón por sus amigos marxistas. El otro gran punto es qué emociones habrán de considerarse "racionales" o "apropiadas", tal que puedan usarse en la arena pública. Para una lectura cognitivista, véase Nussbaum, 2008 y 2009; Elster, 2002. Para una no cognitivista (pero sin quitarle poder activo y útil a las emociones), véase Robinson, 2005.

${ }^{28}$ Empero, no olvidemos el caso Evans y los problemas que sugiere con respecto a lo que podrían algunos esperar de la empatía.
} 
del caso, de tal forma de no ser el juez neutral y abstracto de Weschler ${ }^{29}$ que, por ejemplo, es ciego a las asimetrías entre negros y blancos cuando va a juzgar un caso de ¡injustificada discriminación! (Nussbaum, 1995: 86-88).

Segundo, no sería compulsivo para Amaya quedar aferrada exclusivamente a un punto de vista de primera o tercera persona respecto de los agentes intérpretes sino que podría basarse en un punto de vista de "segunda persona" (Bagnoli, 2007: 43-52, en su discusión con la teoría ética de Richard Moran) de modo tal que la interpretación coherentista orbite sobre la idea de una práctica comunitaria con puntos compartidos a partir de una interacción inteligente (Lekan, 2003: Introduction). Pienso que esta es una opción presente en el propio trabajo de Amaya que, siguiendo a Bratman, resalta el valor de llevar a cabo en forma coherente "acciones colectivas conjuntas". La idea de una práctica compartida no es inocente y va al corazón de varios problemas fundamentales para Amaya, en particular el de cómo escapar a la acusación de que la coherencia no es garantía suficiente de evitación de la "arbitrariedad" de un esquema reputado, pese a ello, coherente. Autores diversos (como Dworkin, 1986: capítulo 5; Raz, 2009: 299322; Wallace, 1988 Lekan, 2003; Will, 1988; Richardson, 1990: 279310 y Richardson, 1997: capítulos 4, 7 y 8; Brandom, 1979: 187-196) comparten, curiosamente, tesis que tienen el mismo "aire de familia": una práctica es una articulación compleja de dos valores en tensión: por un lado, el valor de la continuidad, la estabilidad, la "unidad" de la práctica, por el otro, la necesidad de cambio, adaptación, sensibilidad a la diversidad, al pluralismo, el conflicto, etc. El gran desafío para todos estos autores es cómo conciliar -y si efectivamente es posible hacerlo"continuidad" con "innovación" sin que ciertos criterios básicos, valores, principios, etc., vean alteradas, sustancialmente, su identidad. En suma, se trata de cómo rearmar el barco de Teseo sin que deje de ser el barco de Teseo. Quizás hasta cierto punto esto sea valioso para las

${ }^{29}$ Recuérdese su importante y tan pertinente artículo para temas como el conflicto y el pluralismo titulado "Toward Neutral Principles of Constitutional Law". 
prácticas que nos parecen aceptables (menudo problema a discutir será cuál puede ser un criterio neutral y plausible de "aceptable"). Pero probablemente a veces las prácticas no se consideren ya valiosas, por factores diversos, y habiliten un "cambio de paradigma" "revolucionario". Mi opinión es que la revolución no podría venir, al menos sería muy difícil imaginarlo, de la propia armazón de la práctica, tendiente a conservarla, sino de criterios externos a la misma que conlleven la conformación de una nueva práctica. Un buen criterio de aceptación para cambiar un esquema coherente sería que se tratase, por ejemplo, de un Derecho inmoral sistémicamente (Raz, 2009: 175-179). Por ejemplo, pensemos que éste es el caso con el Derecho del "apartheid". La idea de cómo cambiar desde las propias piezas de ese esquema a ese Derecho ¿es tanto como preguntarse cómo es posible salir del pozo tirándose de los pelos? Lo que quiero incitar a pensar es que, quizás, no sea necesario que Amaya ponga todo su ardor exclusivamente en la coherencia. ¿Por qué no meditar, primero, que ciertas dosis de correspondentismo son compatibles con la coherencia? Supongamos, que quiero saber si el caso x se ajusta o no con las normas sobre la negligencia. Determinar si mi proposición que dice que sí, es correcta o no lo es, constituye la aplicación del modelo de la correspondencia, no de la coherencia. Pero si ahora quiero saber cuál "teoría" se ajusta mejor (explica y justifica mejor) a la negligencia, si la teoría 1 o la 2 , ya es materia de la teoría de la coherencia. Pero todo esto es odiosamente trivial. La perseverante cuestión conceptual con la coherencia es si la misma puede mantener contenidos arbitrarios o no y es aquí donde acudir a una teoría de la correspondencia, por ejemplo apelando a la mejor explicación de hechos morales independientes de las redes coherentes, ya no mostrará compatibilidad entre correspondencia y coherencia: la correspondencia será el único modelo de salvación para escapar de un régimen coherentemente inicuo. Esto, claro, bajo la condición de si se considera que el realismo moral es mejor que el coherentismo moral, es decir, es "salvífico" y no la introducción del demonio dentro del Derecho.

¡El problema es que no sé hasta qué punto lo que estoy planteando puede ser de interés para Amaya! Me consuelo en pensar que puede interesarle, dado el problema planteado: la discusión sobre si la 
teoría de la correspondencia puede ser la barrera que impida la arbitrariedad. Si ella diera un sí, ya estaríamos hablando de un cambio substancial de propuesta en el pensamiento de Amaya. Sin embargo, conocidas "defensas mentales" que todos tenemos podrían impedir que diera este paso contundente.

Pero, me pregunto, ¿en qué niveles, por ejemplo del Derecho, está situando Amaya la discusión sobre la coherencia? Mi impresión es que su trabajo no está enarbolando un requisito de coherencia en términos necesariamente globales. Más bien, su faro se dirige especialmente a situaciones de "aplicación" (o adjudicación) de principios o normas generales para casos particulares. Esta conjetura se corroboraría por dos datos. El primero es que Amaya propugna una "jurisprudencia de agentes"; segundo, su decidido apoyo al "especificacionismo" de Richardson. Este filósofo, de tradición pragmatista en la moral (especialmente en términos de Dewey como Todd Lekan, J. Wallace, Fred Will, etc.), está cavilando sobre dos cosas que sostuve hace poco. Por una parte, cómo preservar la identidad nuclear de normas o principios morales; por el otro, cómo es posible que estas normas o principios cubran situaciones que son irritantemente novedosas. Richardson desestima que los modelos que denomina de la "deducción" y el "balance" sean buenas opciones. Su tesis es que la deducción es muy abstracta y rígida a las peculiaridades particulares de los casos a resolver, mientras el balance es demasiado particularista. Entre ambos se ubicaría el modelo "especificacionista" cuyo espíritu es que no se trata de deducir o balancear, al menos no primariamente, sino de especificar normas generales de un modo parsimonioso tal que tales normas sean aplicables a casos novedosos sin ver vulnerada su identidad básica. La intentona parece interesante en tanto no formulemos la pregunta escéptica de cómo saber - ¡si podemos saber!- si una especificación de una norma es realmente tal o ya supone una traición a la identidad de la norma. Me temo que el modelo especificacionista es importante, sigue siendo sugerente y estimulante de nuestra imaginación ${ }^{30}$, pero todavía no

\footnotetext{
${ }^{30}$ Dicho sea de paso, la "imaginación" moral o legal es un conocido recurso muy similar a la postura especificacionista y empleada para tratar de resolver en
} 
tenemos precisiones de cómo funciona exactamente en la práctica y cuán viable sea su eventual funcionamiento.

10. Quiero finalizar mi ensayo retornando a la cuestión de la "irracionalidad práctica" (que traté párrafos atrás) y a la poca atención, por lo menos en su artículo, que Amaya presta a lo que Elster (2002) llamó la "alquimia mental" (el par emoción-creencia). A lo ya tratado deseo llamar la atención sobre dos aspectos que sólo mencionaré grosso modo. El primero se vincula con la relación entre la coherencia y la identidad personal, un punto demasiado adherido a la importancia que Amaya da a los agentes y su conexión con la coherencia. Ella dice: "se necesita un agente unitario que se sienta confiablemente parte de una comunidad con una identidad específica". Mi inquietud es saber cuánto le interesaría a Amaya explorar esas "fluctuaciones" o, mejor dicho, esas "sucesiones" de "yoes" (Parfit, 2004; Bodei, 2006; Tabucchi, 1998) que complican el análisis de la identidad (no digamos de la responsabilidad) de los agentes a los que ella tanta importancia quiere darles en su teoría de la coherencia. Recordemos que entre las operaciones para restablecer la coherencia, Amaya sostiene que no debe prestársele tanta importancia a las operaciones de "adición" o "sustracción" (promulgación o derogación diría un jurista de estos lares) de las "normas" que provocan la "inconsistencia". Más bien hay que hacer foco en el papel de la "interpretación" como mecanismo de ajuste coherentizador entre principios conflictivos. Pero, esta interpretación coherentizadora en la que piensa Amaya, ¿cuánto depende de la consideración de la identidad de los intérpretes y cómo afecta, a su tiempo, el estudio de la identidad de la comunidad a la que éstos pertenecen? Por otra parte, no me queda claro cuál es, finalmente, la prioridad conceptual del análisis de Amaya: pareciera que son los agentes unitarios, es decir, aquellos que presumiblemente exhiben un yo inmune a las fluctuaciones parfitianas. Pero, por el otro, este agente no es una cápsula cerrada sobre sí misma: pertenece a una comunidad con una identidad específica. ¿Entonces?

forma coherente situaciones desafiantes o "irritantes" como diría Peirce, 1877. Véase, por ejemplo, Boyd White, 1985. 
El segundo aspecto tiene que ver con el valor y alcance que estemos dispuestos a otorgar a la coherencia. Mi tesis general sobre el asunto es que exacerbar, a veces en forma inadvertida, el valor de la coherencia (me refiero a una coherencia full sense que reuniera idealmente todas las características mencionadas por Kress) considerando por tanto que su valor $\mathrm{y}$ alcance es absoluta $\mathrm{e}$ irrevocablemente unitario, completo, comprehensivo, etc., siempre, implicará comprometerse con una visión problemática acerca del Derecho o la moral. Basta apelar al argumento de que sensatamente mirado, sin prejuicios, la pluralidad, novedad, complejidad, etc., de casos novedosos a los que nos enfrentamos en moral o Derecho desmienten esta visión. Sería preocupante, ante mi observación, decir entonces: ¡Peor para el Mundo! ¿Pero no hay algún tufillo a esto cuando, la propia Amaya, admite como un problema el "aislamiento" de las teorías de la coherencia respecto de sus inputs y su relación problemática con la verdad $^{31}$ ? La réplica de Amaya podría ser ésta: las características mencionadas por Kress pueden satisfacerse gradualmente; de modo que puede haber distintas teorías de la coherencia según qué características sus cultores crean poder o prefieran satisfacer. Además, la propia coherencia puede estar afectada por un modo monístico o pluralístico (ver notas a pie 4 y 10 de mi texto) de organizar los principios que forman la red de "socorros mutuos". Sin embargo, si ésta fuera la réplica, ¿no habría cierta prisa desaconsejable en la misma? Yo creo que lo que Kress nos está sugiriendo, correctamente, es que estas características, de ser satisfechas, identificarán la mejor y más plena teoría de la coherencia que valdría la pena seguir. Pero claro: a este punto no puedo saber si la teoría de Amaya quiere ser -o no- una instancia de la mejor y más plena teoría de la coherencia o sólo una versión menor. Probablemente una defensa suya podría ser advertirnos que la mejor y más plena teoría de la coherencia sólo indica un ideal regulativo. Pero de todos modos es necesario saber si su teoría quiere ser regulada por tal ideal. Ello es así por cuanto hay que determinar si: 1) seguir este ideal no tendría ciertos costos a considerar (aquello que la coherencia no nos

\footnotetext{
${ }^{31}$ Como el lector verá, en partes anteriores de este texto he estado rondando esta cuestión.
} 
deja ver, tal como indicaré más adelante) y 2) si tal ideal no es, en realidad, una forma encubierta de ideal utópico, más no regulativo, que por lo tanto quizás habría que descartar. Sería importante, pienso, conocer la opinión de Amaya sobre estas cuestiones imprescindibles.

Ahora bien, en contra de mi tesis general acerca de una coherencia full sense, autores como Weinrib (2005: 339 y ss.) sostendrían que hay una coherencia de este tipo "inmanente" al Derecho lograda por una reconstrucción hegeliana que muestra la inteligibilidad de sus normas y principios. Aunque Weinrib no habla de una "jurisprudencia de agentes" no lo veo tan lejos de Amaya. Como buen hegeliano, Weinrib (¿y Amaya?) vincula agente $y$ comunidad de un modo inextricable y algo así queda sugerido en el párrafo de Amaya antes citado acerca de la identidad de los agentes que son miembros de una comunidad con una identidad específica. Ahora bien, la tesis de Weinrib es que coherencia es sinónimo de inteligible. En consecuencia, habría que concluir que lo "incoherente" es ininteligible fatalmente. Quiero sostener que la literatura puede ser un buen recurso para meditar críticamente sobre este asunto. Pensemos solamente en Molloy de Beckett (véase Nussbaum, 2005: 513-560). Intentar reconstruir la "inteligibilidad" de la búsqueda existencial de Molloy y la persecución policial que hace de él Moran, quizás podría ser una manera muy simplista de entender la obra. Beckett, repetidamente se ha sostenido, coquetea con lo absurdo y no es fácil extraer una lección inteligible de Molloy, de qué es lo que Beckett está queriendo decirnos a través de esta obra. Creo que es sensato aceptar que hay algo de paradoja en ella, además de leve y discreto encanto de aceptar cierta incoherencia y absurdidad del mundo para llegar a ver cosas que una estructura -presuntamentecoherente no nos permitiría ver, por ejemplo, para lo que nos atañe a nosotros los filósofos prácticos: 1) no ver la existencia de un tratamiento jurídico-político asimétrico de cierta clase social; asimetría no captada debido a la presencia de alguna concepción ideológica asumida como neutral y que se acepta que representa del modo más coherente a cierto Derecho y que nubla la visión sobre la existencia de concepciones rivales más deferentes con la clase social 
desfavorecida ${ }^{32}$; 2) no ver que pueda haber conflictos dentro del Derecho (por caso entre "valores-bisagra") para los que no haya una respuesta correcta; 3 ) no ver que pueda haber conflicto intersistemático entre valores jurídicos y extrajurídicos donde no es claro porqué los segundos no deberían derrotar a los primeros o bajo qué condiciones podrían hacerlo; 4) no ver que el pluralismo expresa una legítima desconfianza hacia un consenso totalizante que disminuye cierto valor que podría tener el disenso; 5) no ver las posibles incoherencias ${ }^{33}$ en los intérpretes coherentizadores; 6) no ver que de ciertas incoherencias ideológicas o valorativas en el Derecho pueden surgir cambios que luego consideremos positivos; 7) y un extenso etcétera.

Lo paradójico es que a través de lo absurdo e incoherente podemos con cierto esfuerzo (y aquí habría que ver qué tipo de interpretación ofrecería Amaya) lograr un cuestionamiento a la idea (o mejor aún la metáfora) de que haya algo así como un Dios garante de un orden siempre coherente $e^{34}$ que posibilita la existencia del consenso y la respuesta correcta a la mano siempre. Por suave analogía, si un

${ }^{32}$ Para un sofisticado intento de coherentizar, bajo un esquema hegeliano, concepciones políticas rivales (comunitaristas y liberales) dentro del Derecho, nada mejor que Brudner, 2007. Mostrando las críticas que este intento ha recibido de parte de ambos bandos, por ejemplo en cuanto a su rendimiento para lograr una salida coherente, aceptada por todas las partes, para el problema del aborto, véase Zucca, 2007b.

${ }^{33}$ Véanse mis referencias a Davidson y también la conexión de esta cuestión de incoherencia con lo expuesto en nota a pie 9.

${ }^{34}$ Sobre el histórico, complejo y variado vínculo conceptual entre Derecho y Teología véase, por ejemplo, Chase, 2005. Las imágenes teológicas en el Derecho están presentes de modos diversos; un par de ejemplos pueden ilustrar esto. Primero: la atribución a un legislador de carne y hueso de la etiqueta de "racional" presupone la imputación de rasgos de un ser divino: por ejemplo, "omnisciencia" para contemplar todos los hechos relevantes del futuro y consistencia para generar regulaciones coherentes. Segundo: la conocida teoría del "doble cuerpo del rey", uno humano y otro divino, se ha empleado para explicar que la continuidad del Derecho podría entenderse analógicamente en términos del cuerpo divino que no perece, que continúa pese a las muertes de los cuerpos humanos de los gobernantes o funcionarios. 
jurista nos regalase una descripción que sostiene que cierto Derecho posee parcelas relevantes incoherentes, a lo mejor lo que nos estaría regalando es una formidable crítica de su pretensa coherencia, unidad y estabilidad absolutas; palabras-máscara del terrible funcionamiento del poder, de ese conjunto de "dientes afilados que pueden morder" que es el Derecho (como dijo John Austin alguna vez). Bajo el "discurso de la coherencia" se ocultaría la necesidad de legitimar moralmente al Derecho (Kress, 2005: 533). Pero a lo mejor, ese Derecho podría ser inobjetablemente coherente y aún así no dejaría ser un conjunto de dientes que pueden morder. Moraleja: quizás no importe tanto focalizarnos en la coherencia si creemos que, con ella, o sin ella, el Derecho nos puede morder y que no tiene ninguna legitimidad moral posible para hacerlo, mal que les pese a los que usan a la coherencia como un posible criterio de legitimidad (tal el caso de R. Dworkin). Dicho de otro modo: el jurista que imaginé, un jurista que se me ocurre como beckettiano, estaría diciéndonos que no es posible meter el bicondicional entre "coherente" y "moralmente legítimo". Que esta es una manera errónea de buscar. Que hay que buscar en otro lugar.

A lo mejor estamos "solos en el mundo" (como trasunta el duro mensaje de Beckett) y esto es lo que más debe contar. A este fenómeno de "estar solos" quizás un anarquista lo llamaría tomarse en serio una autonomía moral fuerte de los individuos; autonomía que no tiene -necesariamente, sólo digo, necesariamente- plafón en ninguna garantía de orden o inteligibilidad totales, mucho menos una garantía implícitamente teológica. Sé que éste es un modo heresiarca de interpretar la autonomía moral y que Kant se está revolviendo en su tumba pues, para él, autonomía, y orden inteligible y universal de fines, van de la mano. Pero mi sugerencia no parte de la exégesis; además, hay ejemplos en filosofía (pienso por ejemplo en Adorno o Simmel) que harían una interpretación semejante de la autonomía a la que estoy sugiriendo aquí: una que la defiende pero que le quita el plafón de un orden ABSOLUTAMENTE coherente. El point final de mi argumento no es fortalecer el caos o mostrar júbilo por la posmodernidad (para una reconstrucción de su modus vivendi en el Derecho, Patterson, 205). Son fenómenos que me producen algo de depresión. 
Quizás, después de todo, no tenga un argumento sino más bien algo puramente intuitivo para estimular una reflexión a posteriori más detallada. Mi tesis más específica es que, detrás del discurso coherentista, casi siempre, viene adosado el discurso del consenso uniforme, sea como factum, sea como ideal regulativo a satisfacer. Pero hay otro modo de ver a la autonomía, un modo que parte (o acepta en serio el juego) del disenso (Rescher, 1995: Introduction), del ¡no! de Muguerza (1998) y que por esto cuestiona los presupuestos intocados de orden consensuado coherente que parece adoptar el modelo de Amaya. Posiblemente una nueva respuesta de Amaya podría ser formulada bajo la forma del siguiente interrogante: ¿por qué el disenso tiene que depender del mensaje anarquista y su presunta concepción de autonomía individual? Por cobarde que pueda parecer mi contestación, debo decir que mi referencia a esta concepción ha sido solo el lanzamiento de una sonda dirigida a estimular una discusión y a explorar un resultado que no sé muy bien -debo confesarlo- cuál pueda ser exactamente. Supongamos que a la luz de esta confesión aparto el tema de cómo concebir mejor la autonomía y retengo sólo el punto del disenso. Ahora mi "contra ataque" para Amaya sería, nobleza obliga, una pregunta para ella: ¿qué lugar hay para el disenso ético, jurídico o político en su modelo de coherencia? ¿Es posible respetar el disenso dentro de un mismo sistema y mantener la idea de que la coherencia se encuentra incólume?

En Molloy, Beckett no abjura completamente del orden: deconstruye (Balkin, 2005) uno de índole teológica, para buscar uno más humano ${ }^{35}$. Haber traído a Beckett aquí ha tenido el propósito de sugerir que, a lo mejor, tenemos que rescatar cierta pizca, cierto discreto encanto, leve, muy suave, de incoherencia, que nos permita tener sensibilidad al conflicto, al disenso, a aquellos "inputs" que nuestros sistemas no recogieron y que sería relevante considerar. ¿Podemos permitirnos mantener, entonces, un núcleo acorazado de coherencia pero ser sensibles a cierta dosis de incoherencia?

${ }^{35}$ Un orden más humano debería aceptar, por ejemplo, fenómenos como el conflicto y la mala suerte epistémica o moral como límites para la coherencia tout court. Véase al respecto, Lariguet, 2009b. 
Voy a finalizar mi escrito suponiendo que a esta altura Amaya puede estar "aterrada de la risa". Que podría decir que nos hubiéramos ahorrado este trabajo si hubiésemos hecho esa anhelada caminata desde el Instituto de Investigaciones Filosóficas de la UNAM hasta el MetroBus y que todo habría acabado en una discusión peripatética. Restará, sin embargo, agradecerle su paciencia y la del lector que, con aguardiente, tequila o ajenjo, o sin estas bebidas, me ha seguido línea por línea hasta aquí. 


\section{BIBLIOGRAFÍA}

Aarnio, A. 1990. "La tesis de la única respuesta correcta y el principio regulativo del razonamiento jurídico", Doxa. Cuadernos de Filosofía del Derecho. $N^{\circ} 8$. Alicante.

Alchourrón, C. y Bulygin, E. 1991. "Los Límites de la Lógica y el Razonamiento Jurídico", Carlos Alchourrón y Eugenio Bulygin. Análisis Lógico y Derecho, Centro de Estudios Constitucionales. Madrid.

Alford, Fred. 1992. The Psychoanalytic Theory of Greek Tragedy. Yale University Press. New Haven and London.

Amaya, A. 2008a. "Virtudes Judiciales y Argumentación. Una aproximación a la ética jurídica", Manuscrito Inédito.

Amaya, A. 2008b. "The Role of Virtue in Legal Justification", Manuscrito Inédito.

Aristóteles. 2000. Metafísica. Traducción de Hernán Zucchi. Sudamericana. Bs As.

Atienza, M. 1997. "Los Límites de la Interpretación Constitucional. De nuevo sobre los casos trágicos". Isonomía. Revista de Teoría y Filosofía del Derecho. $\mathrm{N}^{\circ}$ 6. México.

Atienza, M. 2008. "Prólogo a Dilemas y Conflictos Trágicos. Una investigación conceptual de Guillermo Lariguet". PalestraTemis. Lima-Bogotá.

Atria, F. 2005. "Sobre las lagunas". En Atria, Moreso, Bulygin, Ruiz Manero, Navarro. Sobre las Lagunas en el Derecho. Marcial Pons. Madrid.

Audi, R. 2003. Epistemology. A contemporary introduction to the theory of knowledge. Routledge. New York and London.

Bagnoli, C. 2006. "Breaking Ties. The Significance of Choice in Symmetrical Moral Dilemmas". Dialectica. 60.

Bagnoli, C. 2007. "The Authority of Reflection". Theoria. 58.

Balkin, J. 2005. "Deconstruction", en A Companion to Philosophy of Law and Legal Theory, Editada por Dennis Patterson. Blackwell Publishing. 
Blackburn, S. 1996. "Dilemmas: Dithering, Plumping, and Grief", en

H. Mason (ed) Moral Dilemmas and Moral Theory, Oxford, pp. 127-139. Oxford University Press.

Bodei, R. 2006. Destinos Personales. La era de la colonización de las conciencias. Traducción y prólogo de Sergio Sánchez. Cuenco de Plata. Bs As.

Booth, W. 1988. A Company we Keep. An Ethics of Fiction. California University Press. California.

Boyd White, J. 1985. The Legal Imagination. The University of Chicago Press. Chicago and London.

Brandom, R. 1979, "Freedom and Constraint by Norms", American Philosophical Quaterly, Vol. 16, No.3, Pittsburg.

Brandom, R. 1998. Making it Explicit. Reasoning, Representing, and Discursive Commitment. Harvard University Press, Harvard.

Brandom, R. 2001. Articulating Reasons. An Introduction to Inferentialism. Harvard University Press. Harvard.

Brudner, A. 2007. Constitutional Goods. Oxford University Press. Oxford.

Caracciolo, R. 1994. "El Concepto de Laguna: Descripción o Prescripción". R. Caracciolo. La Noción de Sistema en la Teoría del Derecho. Fontamara. México.

Chang, R. 1997, "Introduction", in Ruth Chang (Ed), Incommensurability, Incomparability and Practical Reason, Harvard University Press, Cambridge.

Chase, E. 2005. "Law and Theology", en A Companion to Philosophy of Law and Legal Theory, Editada por Dennis Patterson. Blackwell Publishing.

Dancy, J. 1985. Epistemología Contemporánea. O Saber da Filosofia. Lisboa.

Davidson, D. 1981. "Las Paradojas de la Irracionalidad". Versión castellana de G. Carrió y E. Rabossi. Análisis Filosófico. Vol. 1. No 1. Bs As. 
Dworkin, R. 1983. Los Derechos en Serio. Traducción de Marta Guastavino. Planeta Agostini. Barcelona.

Dworkin, R. 1986. Law's Empire. Belknap Press of Harvard University Press. Harvard.

Dworkin, R. 2005. "Moral Pluralism”, en R. Dowrkin. Justice in Robes. The Belknap Press of Harvard University Press. Cambridge-Massachusetts-London.

Elster, J. 1995. Juicios Salomónicos. Las limitaciones de la racionalidad como principio de decisión. Traducción de Carlos Gardini. Gedisa. Barcelona.

Elster, J. 2002. Alquimias de la Mente. La Racionalidad y las Emociones. Traducción de Albino Santos Mosquera. Paidós. Barcelona.

Engel, P. 2002. Truth. Acumen.

Ernst, C. 1992. Los Derechos Implícitos. Lerner. Córdoba.

Eskridge, Jr. y Levinson S. 1998 (editores). Constitutional Stupidities, Constitutional Tragedies. New York University Press. New York.

Greenspan, P.S. 1995. Practical Guilt. Moral Dilemmas, Emotions and Social Norms, Oxford. Oxford University Press.

Guastini, R. 1999. Distinguiendo. Estudios de Teoría y Metateoría del Derecho. Traducción de Jordi Ferrer. Gedisa. Barcelona.

Hampshire, Stuart, 2000, Justice is Conflict, Princeton University Press, Chichester, West Sussex.

Harman, G. 1983. La Naturaleza de la Moralidad. Una introducción a la ética. UNAM. Instituto de Investigaciones Filosóficas. México.

Harman, G. 2003. "The Future of the A Priori". http://www.princeton.edu/ harman/Papers/FutureAP.html

Hart, H.L.A. 2001. "American Jurisprudence Through English Eyes: The Nightmare and the Noble Dream", en Essays in Jurisprudence and Philosophy. Clarendon Press.

Hurtshouse, R. 2001. On Virtue Ethics, Oxford. Oxford University Press. 
Kalpokas, D. "Pragmatismo, Empirismo y Representaciones. Una propuesta acerca del papel epistémico de la experiencia", Análisis Filosófico. Vol. XXVIII, N² 2. Bs. As.

Kress, K. 2005. "Coherence", en A Companion to Philosophy of Law and Legal Theory, Editada por Dennis Patterson. Blackwell Publishing.

Lariguet, G. y Martínez, D. 2008. Els Dilemes Morals. Editorial de la Universidad Oberta de Catalunya.

Lariguet, G. "Conflictos Trágicos Genuinos y Respuesta Correcta. En torno a algunas ideas de Ronald Dworkin", Revista de la Facultad de Derecho de la UNAM, N²46. México.

Lariguet, G. 2007a. Dogmática Jurídica y Aplicación de Normas. Prólogo de Fernando Atria. Doctrina Jurídica Contemporánea. Fontamara. México.

Lariguet, G. 2007b. "Inconmensurabilidad, Derecho y Límites de la Racionalidad Práctica. A propósito de Law-Making and Incommensurability de Henry Mather", Cuadernos Electrónicos de Filosofía del Derecho, № 16 . Valencia.

Lariguet, G. 2008. Dilemas y Conflictos Trágicos. Una Investigación conceptual. Prólogo de Manuel Atienza. Palestra-Temis. Lima-Bogotá.

Lariguet, G. 2009a. "Los Dilemas Morales Qua Límites de la Racionalidad Práctica”, en Volumen de las Jornadas sobre Ética y Conflictividad, Academia Nacional de Ciencias de Buenas Aires, Revista de la Universidad de Ciencias Empresariales de Bs. As.

Lariguet, G. 2009b. "La Ética frente a los Dilemas Trágicos. Guerreros, Pacificadores y Cirujanos", A Parte Rei. 64. Revista de Filosofía. España.

Lekan, Todd, 2003. Making Morality. Pragmatist Reconstruction in Ethical Theory, Vanderbilt University Press. Canadá.

Malem Seña, J. 2001. “Pueden las malas personas ser buenos jueces”, Doxa. Cuadernos de Filosofía del Derecho. N 24. Alicante. 
Martínez, D. 2007. Conflictos Constitucionales, Ponderación e Indeterminación Normativa. Marcial Pons. Madrid.

McConnell, T. "Moral Dilemmas", Stanford Encyclopedia of Philosophy, http://plato.stanford.edu/entries/moraldilemmas 2002.

McCormick, N. 2005. Rhetoric and the Rule of Law. A Theory of Legal Reasoning. Oxford University Press. Oxford.

McDowell, Jh. 1997. "Brandom on Representation and Inference", Philosophy and Phenomenological Research". Vol. LVII. $\mathrm{N}^{\mathrm{o}} .1$.

McDowell, Jh. 2003. Mente y Mundo. Traducción de Miguel Ángel Quintana Paz. Ediciones Sígueme.

Martin, C. 2003 (09-15). "Review of Truth and Truthfulness of Bernard Williams", Notredame Philosophical Review.

Michelon. C. 2006. Being Apart From Reasons. The role of reasons in public and private decision-making. Springer.

Muguerza, Javier, 1998. Ética, Disenso y Derechos Humanos. Argés, Madrid.

Nagel, Th. 2000. La Última Palabra. Traducción de Paola Bergallo y Marcelo Alegre. Gedisa. Barcelona

Navarro, P. 2003. "Normas Derivadas". Versión Manuscrita. (trabajo recogido en su obra Los Límites del Derecho. Estudios sobre los compromisos conceptuales del positivismo jurídico. 2005. Temis. Bogotá)

Nussbaum, M. 1995. Poetic Justice. The literary imagination and public life. Beacon Press. Boston.

Nussbaum, M. 2005. "Emociones Narrativas: la genealogía del amor en Beckett", en Martha Nussbaum. El Conocimiento del Amor. Ensayos sobre Filosofía y Literatura. Traducción de Rocío Orsi Portalo y Juana María Inarejos Ortiz. Mínimo Tránsito A. Machado Libros. Madrid.

Nussbaum, M. 2008. Upheavals of Thought. The intelligence of emotions. Cambridge University Press. Cambridge. 
Nussbaum, M. 2009, La Terapia del Deseo. Teoría y Práctica en la Ética Helenística, Traducción de Miguel Candel, Paidós Básica, Barcelona-Buenos Aires, México.

Parfit, D. 2004. Razones y Personas. Traducción y estudio introductorio de Mariano Rodríguez González. Mínimo Tránsito. A. Machado Libros. Madrid.

Patterson, D. 2005. "Postmodernism", en A Companion to Philosophy of Law and Legal Theory, Editada por Dennis Patterson. Blackwell Publishing.

Peczenik, A. 2000. “¿Por qué tiene que ser coherente el razonamiento jurídico?", Derecho y Razón. Versión castellana de E. Garzón Valdés. Fontamara. 74. México.

Peirce, Ch. S. 1877 (noviembre). "The Fixation of Belief”. Popular Science Monthly. http://www.peirce.org/writings/p107.html

Pereira, G. 2004. Medios, Capacidades y Justicia Distributiva. UNAM. Instituto de Investigaciones Filosóficas. México.

Pérez Bermejo, J.M. 2006. Coherencia y Sistema Jurídico. Marcial Pons. Madrid.

Platts, M. 1998. Realidades Morales. Ensayo sobre Psicología Filosófica. Paidós. UNAM. Instituto de Investigaciones Filosóficas. México.

Rae, S, 1995, Moral Choices. An Introduction to Ethics, Zondervan, Michigan.

Ratti, G. 2007. "La coherentización de los sistemas jurídicos", Cuadernos Electrónicos de Filosofía del Derecho, 15, Valencia.

Raz, J. 2009. “About Morality and the Nature of Law”, en Joseph Raz. Between Authority and Interpretation. Oxford University Press. Oxford.

Raz, J. 2009. “Incorporation by Law”, en Joseph Raz. Between Authority and Interpretation. Oxford University Press. Oxford.

Raz, J. 2009. "Interpretation: Pluralism and Innovation”, en Joseph Raz. Between Authority and Interpretation. Oxford University Press. Oxford. 
Raz, J. 2009. "On The Authority and Interpretation of Constitutions: Some Preliminaries", en Joseph Raz. Between Authority and Interpretation. Oxford University Press. Oxford.

Redding, P. 2007. Analytical Philosophy and the Return of Hegelian Thought. Cambridge University Press. Cambridge.

Richardson, H.S, 1990, "Specifying Norms as a Way to Resolve Concrete Ethical Problems", Philosophy and Public Affairs, Vol. 19, $\mathrm{N}^{\circ} 4$.

Richardson. H. S. 1997. Practical Reasoning About Final Ends. Cambridge University Press. Cambridge.

Robinson, J. 2005. Deeper than Reason. Emotion and its Role in Literature, Music, and Art. Oxford University Press. Oxford.

Rodríguez, J. 1999. "Lagunas Axiológicas y Relevancia Normativa". Doxa. Cuadernos de Filosofía del Derecho. $\mathrm{N}^{\mathrm{o}} 22$. Alicante.

Rorty, R. 1996. Consequences of Pragmatism. University of Minnesota Press. Minneapolis.

Ruiz Manero. J. 2005. "Algunas concepciones del Derecho y sus Lagunas”. En Atria, Moreso, Bulygin, Ruiz Manero, Navarro. Sobre las Lagunas en el Derecho. Marcial Pons. Madrid.

Schauer, F. 2009. Thinking like a Lawyer. An Introduction to Legal Reasoning. Harvard University Press. Harvard.

Scheler, M. 1961. "Acerca del Fenómeno de lo Trágico", en El Santo, El Genio, El Héroe, trad. Elsa Tabernig, Bs. As., Editorial Nova.

Sollum, L. and Farrelly. C. 2008. Virtue Jurisprudence, Palgrave MacMillan Publishers Limited.

Tabucchi, A. 1998. Sostiene Pereira. Traducción Carlos Gumpert y Xavier Rovira. Anagrama.

Tribe, L. 2008. The Invisible Constitution. Oxford University Press. Oxford. 
Wallace, J. 1988. Moral Relevance and Moral Conflict. Cornell University Press. Cornell.

Weinrib, E. 2005. "Legal Formalism", en A Companion to Philosophy of Law and Legal Theory, Editada por Dennis Patterson. Blackwell Publishing.

Will, F. 1988. Beyond Deduction. Ampliative Aspects of Philosophical Reflection. Routledge. New York and London.

Williams, B. 2002. Truth and Truthfulness. An Essay in Genealogy. Princeton University Press. Princeton-London.

Wisdom, Jh. 1986. "Filosofía, Metafísica y Psicoanálisis", en Javier Muguerza Compilador. La Concepción Analítica de la Filosofía. Alianza. Madrid.

Zagzebski, L. 1996. Virtues of the Mind. An Inquiry into the Nature of Virtue and the Ethical Foundations of Knowledge, Cambridge. Cambridge University Press.

Zucca, L. 2007a. Constitutional Dilemmas. Conflicts of Fundamental Legal Rights in Europe and USA. Oxford University Press. Oxford.

Zucca, L. 2007b, "Too Good to be True", Canadian Journal of Law and Jurisprudence, Vol. XX. $\mathrm{N}^{\mathrm{o}} 1$. 